\title{
WestVirginiaUniversity
}

THE RESEARCH REPOSITORY @ WVU

Graduate Theses, Dissertations, and Problem Reports

2004

\section{Mathematical writing in the elementary classroom}

Dana D. McCauley

West Virginia University

Follow this and additional works at: https://researchrepository.wvu.edu/etd

\section{Recommended Citation}

McCauley, Dana D., "Mathematical writing in the elementary classroom" (2004). Graduate Theses,

Dissertations, and Problem Reports. 2636.

https://researchrepository.wvu.edu/etd/2636

This Dissertation is protected by copyright and/or related rights. It has been brought to you by the The Research Repository @ WVU with permission from the rights-holder(s). You are free to use this Dissertation in any way that is permitted by the copyright and related rights legislation that applies to your use. For other uses you must obtain permission from the rights-holder(s) directly, unless additional rights are indicated by a Creative Commons license in the record and/ or on the work itself. This Dissertation has been accepted for inclusion in WVU Graduate Theses, Dissertations, and Problem Reports collection by an authorized administrator of The Research Repository @ WVU.

For more information, please contact researchrepository@mail.wvu.edu. 


\title{
Mathematical Writing in the Elementary Classroom
}

\author{
Dana D. McCauley
}

A dissertation submitted to the College of Human Resources and Education

at West Virginia University in partial fulfillment of the requirements

for the degree of

\section{Doctor of Education}

in

Curriculum \& Instruction

Sandra Atkins, Ph.D., Chair Ardeth Deay, Ph.D.

Katherine Mitchem, Ph.D.

Sam Stack, Ph.D.

Patricia Mullinix, Ph.D.

Department of Curriculum \& Instruction

Morgantown, West Virginia

2004

Keywords: mathematics, dialogue, discussions, writing 


\section{ABSTRACT \\ Mathematical Writing in the Elementary Classroom}

\section{Dana D. McCauley}

In this study, fourth and fifth grade students at River View Elementary participated in mathematics activities requiring written and oral dialogue. These dialogues were analyzed to determine how their mathematical understandings were reflected in their written and oral discussions. An examination of pre and post mathematical writing occurred to determine the effect the dialogue had on students' mathematical writing. Students were given a mathematics problem to solve. After reading the mathematics problem, each student wrote questions they had regarding the problem as well as a request for additional information that they felt was needed to solve the problem. Students exchanged their writing with a classmate and responded to their questions and/or requests. After several repetitions of this sequence, each pair of students dialogued with another pair of students and discussed remaining questions and concerns regarding the problem. Students independently solved the story problem and justified their answer in writing. A class discussion was held and answers and justifications shared. This process resulted in significant gains in students' ability to complete Brief Constructed Responses items modeled after the Maryland School Assessment. In addition, students' beliefs about mathematics evolved from math as simply computing and a silent activity to math involving strategies and being a sensible activity. 


\section{ACKNOWLEDGEMENTS}

Throughout this journey I have been blessed with support from many family members and friends. As I reflect over the last several years I am reminded of their words of encouragement as well as their actions that kept my energy level high and reinforced my belief that what I wanted to accomplish was within reach. It is here that I wish to acknowledge and thank them for all they have done. To Mom, Dad, Michelle, and Jeanne, who knew I would finish...even when I had doubts. Your words of encouragement arrived when I needed them the most. To my staff, who remind me daily that what we do makes a difference. You all inspire me to be the best I can be. To each of my committee members; Dr. Deay, Dr. Mitchem, Dr. Stack, and Dr. Mullinix, for taking time out of your busy lives to guide and share this experience with me. To my committee chair, Dr. Sandy Atkins, who made each of my “emergencies” her priorities. You have gone above and beyond your call of duty, not many chairs color code their editing marks! Your high standards caused me to reach beyond what I thought was possible. To my students who answered the tough questions and gave me much to think about - I will be forever grateful. To Holly who was crazy enough to embark on this journey with me. I cherish your friendship and I am grateful for your reality checks! I could not have asked for a better driving partner and know I would not have made it without your writing supplies! Most of all I need to thank Jeff, Cooper, and Kenzie. Many things in our lives were put on hold so I could finish what I started. The sacrifices you have made have not gone unnoticed. Thank you for allowing me to take the time and prove to myself I could do it. You are my inspiration and I love you! 


\section{Table of Contents}

Chapter 1 Introduction: Turning the Corner ....................................................

Chapter 2 Literature Review: Asking for Directions........................................10

Chapter 3 Methodology: Taking the Scenic Route ............................................24

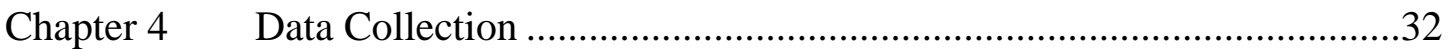

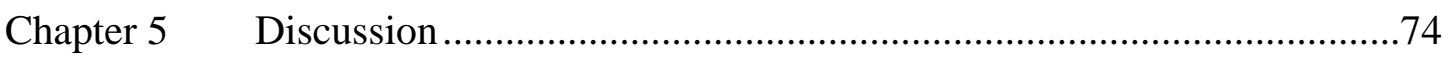

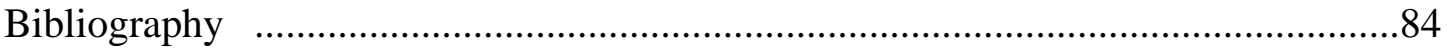

Appendix A Brief Constructed Response Sample Item ......................................96

Appendix B Brief Constructed Response Rubric ................................................97

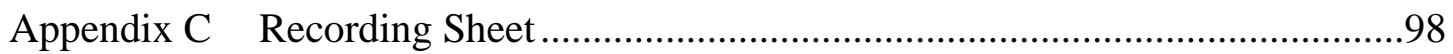

Appendix D Dialogue Journaling Activities ..................................................100

Appendix E $\quad$ Pre-Brief Constructed Response Items ...........................................120

Appendix F Post Brief Constructed Response Items ........................................128 
List of Tables

Brief Constructed Response Scores ......................................................................62 
Figure 1 - The Instructional Design Research Model ..............................................27

Figure 2 - Aaron’s First Attempt ....................................................................46

Figure 3 - Aaron Offers Suggestions...............................................................47

Figure 4 - Aaron's Attempt to Make Math Strategic ....................................................48

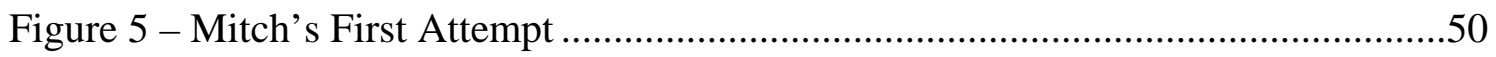

Figure 6 - Mitch Acknowledges His Mistake ........................................................51

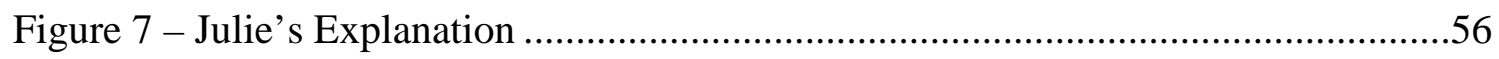

Figure 8 - Julie Convinces Her Partner ...................................................................57

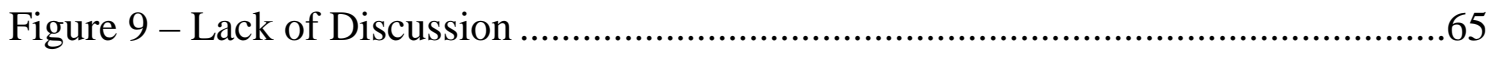

Figure 10 - Discussions Begin ...................................................................67

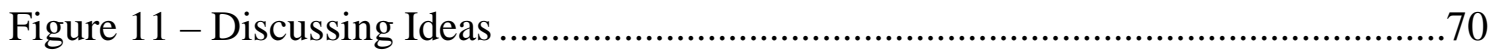

Figure 12 - Fraction Explanation 1 ............................................................... 71

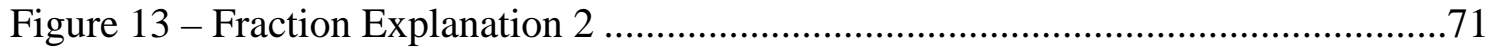

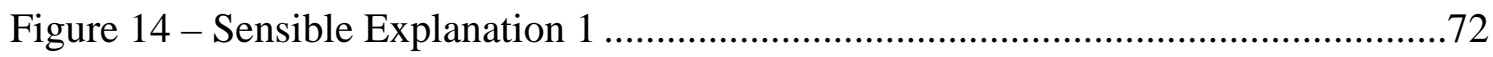

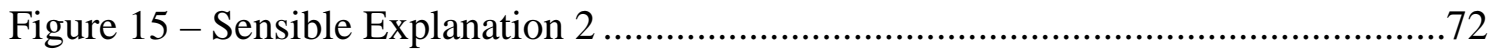

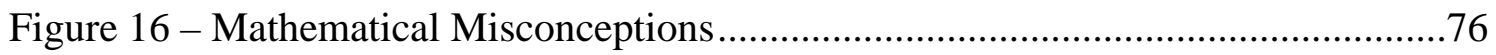


Chapter 1

Introduction: Turning the Corner

It was a simple word problem. I was certain that my fourth and fifth grade students had solved many like it before; and, therefore, I was not expecting anything out of the ordinary. After reading the problem, I turned to the class and asked, "Okay, how do you think we should solve this problem?" As I looked out I saw the usual show of hands and the effort many were making to avoid eye contact with me. Jimmy, a rather active and verbal student, began waving his arm and making his usual "Oh, I know, I know" sounds. I read the problem once more and turned to Jimmy, "Alright Jimmy, how should we solve the problem?" Confidently he stated, "Add." "What are we going to add?" I asked. "Just add the numbers," he shot back. "Why?” I replied. "Okay then subtract," he sighed, seeming disappointed. "I didn't say you were wrong to add, I just want to know why," I defended. "Call on someone else," he requested. "Oh my golly, he really can't tell me why he thinks we should add," I thought. I looked out over the class again and 25 pairs of eyes seemed to glare back at me. In that moment I realized that none of them would be able or willing to give me a good reason. I knew then that I had been leading my students down the wrong road...but I was about to turn the corner. This exchange with Jimmy became an "ah, ha!" moment that will stick with me forever (September, 2003).

At the beginning of the 2003-2004 school year I had a goal for my mathematics class. By June, students would have a deep understanding of mathematics and an ability to engage in mathematical dialogue. During the previous year, I taught grade five 
mathematics for the first time and did not feel my students understood the content. They struggled to explain their reasoning and did not see the connections between mathematics concepts. At that time it was about survival. I was not sure how the content should be organized or how I should lead the lessons. As a veteran teacher teaching a new content area, I did what I said I would never do; I used the mathematics textbook to sequence my instruction instead of my students' needs. With one year under my belt, I was ready for a new start this year. In my mind I had our destination planned.

I had the extra challenge of teaching mathematics to students in a combined grade four and grade five classroom, but I was confident that if I focused on the Standards (NCTM, 2000) and Voluntary State Curriculum (Maryland State Department of Education, 2004), we would reach our destination. While my lessons were filled with engaging, hands-on, mathematics activities, my students were lost when it came to justifying or even talking about mathematics. I was convinced that my students needed me to lead the discussions and activities and that by simply outlining specific mathematical steps I would assist them in reaching our destination faster. In reality, I was creating road blocks. After the exchange with Jimmy, I realized that the route I chose for the class was not going to lead us to our destination. I needed to change what was happening in our class and take a new route...so I turned the corner.

\section{Finding the Right Road Map}

Turning the corner would mean looking at my mathematics class differently. It would mean making changes in my role and the role of my students. School mathematics involves more than computing. We expect students to reach a deeper level of 
mathematical understanding and to communicate that understanding to us (Millard, Oaks, \& Sanders, 2002; Baxter, Woodward, \& Olson, 2001; NCTM, 2000; Smith, 1996). In 1989, the National Council of Teachers of Mathematics (NCTM) called for changes in mathematical content and processes in the Curriculum and Evaluation Standards for School Mathematics (NCTM, 1989). This document was followed by guidelines for changing instruction (NCTM, 1991) and assessment (NCTM, 1995). In 2000, the NCTM unveiled the Principles and Standards for School Mathematics (PSSM). This document consolidated the ideas in the previous three documents and was expanded to include PreKindergarten.

Among the ten Standards outlined in the PSSM (2000) is Reasoning and Proof. This Standard emphasizes the importance of students understanding that mathematical conjectures should be tested and defended or proved (NCTM, 2000). Communication is key to this process and can be accomplished verbally, through representations, or in writing. The importance of these forms of communication is discussed in the Communication Standard of the PSSM (2000). The most important aspect of communicating mathematical understandings is student reflections and refining of their thinking (NCTM, 2000).

In addition to the PSSM (2000), the emphasis and value placed on high-stakes testing have also created a need for a change. Throughout the year there is much talk about "the test" and what will happen if our students do not do well on "the test." Teachers and administrators become consumed by what the test looks like, how it will be scored, and the content that will be assessed. The pressures mount when local schools are 
put on probation because a certain subgroup of students, such as a specific racial/ethnic group or students with special needs, did not reach proficiency on last years' test. In Maryland, this test is the Maryland School Assessment (MSA), (Maryland State Department of Education, 2004). This criterion and norm referenced assessment is Maryland's attempt to meet the federal regulations stated in the No Child Left Behind Act of 2001 (Maryland State Department of Education, 2004). According to this Act, any school receiving federal funding must have $100 \%$ of its students scoring at the proficient level in reading and mathematics by the year 2014. This proficient level in Maryland is achieved by earning a pre-established minimum score established by the State as necessary to demonstrate mastery of the content.

The NCTM Standards (2000) guided the development of the Maryland Voluntary State Curriculum (Maryland State Department of Education, 2004). The Voluntary State Curriculum was the principal guide in determining the Maryland School Assessment (MSA) items. Proficiency standards and standards defining Adequate Yearly Progress (AYP) have been identified by the State of Maryland, and each school is required to meet these standards or face a series of consequences outlined by the state. Included in the elementary mathematics assessments are Selected Response and Brief Constructed Response (BCR) items. On the sections of the assessment with BCR items, students are expected to describe, justify, and/or explain their answers. While we have raised expectations for student performance, we have not changed our instructional practices.

One requirement of the No Child Left Behind legislation (Maryland State Department of Education, 2004) is that the Maryland School Assessment program assess 
the knowledge and understandings of all students. Students who are identified with a learning disability in mathematics must be administered the same assessment as their grade level peers. This mandate creates an instructional challenge for both general and special education teachers. Students who struggle in mathematics typically learn mathematics in isolated chunks, practicing the rules and procedures modeled by the teacher (Baxter, Woodward, \& Olson, 2001; Knuth \& Jones, 1991). These students view mathematics only as a set of procedures and approach it mechanically (Goldman \& Hasselbring, 1997). The literature tells us that engaging students in activities involving discussions (Millard, Oaks, \& Sanders, 2002; Whitin \& Whitin, 2002; Burns \& Silbey, 2000; Cobb, Wood, \& Yackel, 1993) and writing (Whitin \& Whitin, 2002; Burns \& Silbey, 2000; DiPillo, Sovchik, \& Moss, 1997; Pugalee, 1997; Quinn \& Wilson, 1997; Rudnitsky, Etheredge, Freeman, \& Gilbert, 1995; Artzt, 1994; McIntosh, 1991) is effective for helping them clarify their thinking and enriching the thinking of their peers. As a form of communication, writing helps teachers assess student learning which in turn helps teachers plan future instruction (McIntosh \& Draper, 2001; Quinn \& Wilson, 1997; Burns, 1995; Dusterhoff, 1995; Winograd \& Higgins, 1994-5; Gaustad \& MessenheimerYoung, 1991).

\section{Taking the Scenic Route}

There is a comfort in knowing what to expect. Routine is consistent, and consistency is a good thing. We want order in our classrooms and we, as teachers, want to be heard. Students have to listen; there is so much content to cover that we do not take time to stop and reflect. In many mathematics classrooms, teachers typically engage in a 
telling pedagogy (Draper, 2002; Baxter, Woodward, \& Olson, 2001; Smith, 1996). While this style of teaching emphasizes mathematical procedures, it does little to promote reasoning and communication (Draper, 2002; Baxter, Woodward, \& Olson, 2001; Kazemi \& Stipek, 2001; Smith, 1996; Gregg, 1995; O’Brien, Stewart, Moje, 1995) and does not meet the instructional needs of all students (Tomlinson, 2001, Silver, Strong \& Perini, 2000). Good teaching involves differentiation (Tomlinson, 2001; Silver, Strong \& Perini, 2000; Mercer \& Lane, 1996), and every student needs something a little different. As educators, we need to investigate students' understandings in order to create an environment that is conducive to their learning. To obtain this information students need a means for unpacking their thinking and communicating their understandings to the teacher. All children should be challenged. This is not a matter of covering more difficult topics earlier in their academic career, but of challenging them to stretch their thinking, make connections and communicate the understandings (Burns \& Silbey, 2000).

The NCTM Standards (2000) call for student-centered classrooms, where students are engaged in activities emphasizing problem solving, reasoning, and communication. While this educational shift is expected to help students gain meaningful and useful mathematical knowledge, instructionally it is more challenging (Kazemi \& Stipek, 2001; Franke, Carpenter, Fennema, Ansell, \& Behrend, 1998; Fennema, Carpenter, Franke, Levi, Jacobs, \& Empson, 1996; Smith, 1996). Teachers are being asked to reconceptualize their views of effective mathematics instruction and make fundamental changes (Draper, 2002; Fennema, Carpenter, Franke, Levi, Jacobs, \& Empson, 1996; Smith, 1996). 
The Principles and Standards for School Mathematics (NCTM, 2000) explain that because mathematics is often represented in symbols, oral and written communication about mathematical ideas is not always recognized as an important part in mathematics (p.60). These Standards describe how talking, drawing, and writing give students the opportunity to justify their thinking, formulate questions, and summarize important insights (NCTM 2000, p.60). To accomplish this in the classroom, teachers need to relinquish some of the control they typically exert. Typically, it is the teacher who demonstrates the correct mathematical procedure. However, students modeling their solutions have been shown to promote the same problem solving among peers as when the teacher modeled the solution (Thornton \& Langrall, 1997). By allowing students to ask questions of one another, discover the connections among concepts, and reach mathematical understanding by making mistakes, we create a rich learning environment (Millard, Oaks, \& Sanders, 2002; Baxter, Woodward, \& Olson, 2001; Burns \& Silbey, 2000; Smith, 1996; Ball, 1993).

It is difficult not to intervene when a student is “doing” his math incorrectly. After all, it is the teacher's role. Or is it? Is it the teacher's responsibility to prevent students from ever having a wrong answer? Or, is the teacher’s responsibility to provide experiences that help students grow and develop mathematical understandings, even if that means sometimes getting the wrong answer? In teaching content and processes, teachers must encourage students to take risks in their learning and become active participants in the classroom (Blum, Lipsett, \& Yocom, 2002; Burns \& Silbey, 2000; Wall \& Dattilo, 1995). However, typical mathematics activities involve the teacher 
leading the lesson and class discussions (Draper, 2002; Millard, Oaks, \& Sanders, 2002;

Baxter, Woodward, \& Olson, 2001; Kazemi \& Stipek, 2001) which involve only a minority of students while the rest wait to be told what to do (Kazemi \& Stipek, 2001). Turning the Corner

My "ah, ha” moment with Jimmy had forced me to reexamine my instructional techniques. As I searched for ways to help students build their mathematical understandings and ability to communicate those understandings, I realized that my role needed to change. I needed to engage students in activities that would cause them to wrestle with the concepts, argue their points, and develop understandings. I needed to allow them time to reflect and discuss their thoughts so that before a student, like Jimmy, changed his answer he knew why he was doing it.

As I turned the corner I asked myself, "What instructional techniques could I use to promote mathematical understandings and improve my students’ written justifications?” Through a review of the literature I became familiar with a form of conversational writing known as dialogue journaling (Perry, 2001; McGrath, 1992; Gaustad \& Messenheimer-Young, 1991; Bode, 1989). Although there is limited research on this technique, it is a means for students to begin thinking about the problem and documenting their thoughts and questions. Small group discussions provide students the opportunity to verbalize their thinking and hear the opinions of others. Would coupling the dialogue journals with small group oral discussions enable students to clarify and deepen their mathematical understandings? Would these techniques help prepare students for writing justifications? Within this study I investigated the following questions: 
1. What is the effect of dialogue journals and oral discussions on students' mathematical writing?

2. How are students' mathematical understandings reflected in their written and oral discussions? 


\section{Chapter 2}

Literature Review: Asking For Directions

Creating the Need to Travel a New Route

Traditionally, mathematics classrooms were structured with lessons that emphasized basic facts and computation rules and procedures. The teacher would introduce a mathematics problem, demonstrate the steps for solving the problem, and provide practice for the students to solve similar problems (Draper, 2002; Cobb, 1999; Smith, 1996; Knuth \& Jones, 1991). However, reform efforts in mathematics call for major changes in what students should know and be able to do in mathematics K-12. These changes were outlined in the Curriculum and Evaluation Standards for School Mathematics (NCTM, 1989). In addition to content changes, the Standards (1989) address the processes students should engage in to learn mathematics. The change in both content and process, led to recommendations for instructional changes in mathematics classrooms (NCTM, 1991) and in the way we assess students (NCTM, 1995). In 2000, the National Council of Teachers of 
Mathematics unveiled the Principles and Standards for School Mathematics (PSSM). This document consolidated the ideas in the previous three documents and was expanded to include guidelines for Pre-Kindergarten mathematics. Among the ten Standards outlined in the PSSM (2000) is Reasoning and Proof. Contradicting traditional teaching methods in which procedures were the most important aspect in mathematics, this Standard emphasizes the importance of students understanding that mathematical conjectures should have reasons (NCTM, 2000). "Being able to reason is essential to understanding mathematics. By developing ideas, exploring phenomena, justifying results, and using mathematical conjectures in all content areas...students should see and expect mathematics to make sense” (NCTM, 2000, p. 56). The sophistication of justifications, conjectures, and proofs is dependent on the age and experience of the child. However, the Reasoning and Proof Standard suggests that even young children should be taught to make explicit the knowledge they use to solve a mathematical problem. When asked to justify an answer many students assume their response was wrong and attempt to correct their perceived mistake. Cai and Jakabcsin (1996) suggest that the reason students react this way is because the practice of explaining mathematical understandings is rare. Students are not frequently asked to provide mathematical explanations when responding to a problem. Mathematics lessons which encourage developing and explaining understandings differ from the traditional mathematics lessons and rest on several beliefs (Kazemi \& Stipek, 2001):

(a) explanations consist of mathematical arguments, not simply procedural descriptions or summaries; 
(b) mathematical thinking involves understanding relations among multiple strategies;

(c) errors provide opportunities to reconceptualize a problem, explore contradictions in solutions, or pursue alternative strategies; and

(d) collaborative work involves individual accountability and reaching consensus through mathematical argumentation.

The need to communicate mathematical knowledge is necessary to meet the Reasoning and Proof Standard and can be accomplished orally, through representations, or in writing (NCTM, 2000). These forms of communication are essential elements in mathematics and are discussed in the Communication Standard of the PSSM (2000). Communicating mathematical understandings requires that students reflect on and refine their thinking (NCTM, 2000).

The Communication Standard suggests that instructional programs should enable students to (p. 60):

*organize and consolidate their mathematical thinking through communication;

*communicate their mathematical thinking coherently and clearly to peers, teachers, and others;

*analyze and evaluate the mathematical thinking and strategies of others;

*use the language of mathematics to express mathematical ideas precisely. Students need experiences that will enable them to think mathematically as well as communicate their mathematical thinking (Millard, Oaks, \& Sanders, 2002; Baxter, Woodward, \& Olson, 2001; Fraivillig, Murphy, \& Fuson, 1999; Cai \& Jakabcsin, 1996; 
Williams \& Baxter, 1996; Cobb, Wood, Yackel, 1993; Cobb, Wood, Yackel, \& McNeal, 1992; Knuth \& Jones, 1991) if they are to reach the high expectations described in these Standards. The mathematical tasks presented to students should require them to participate in discourse (NCTM, 2000). Students need to engage in learning opportunities where they discuss, revise, and defend their mathematical understanding (Millard, Oaks, \& Sanders, 2002; Baxter, Woodward, \& Olson, 2001; NCTM, 2000; Fraivillig, Murphy, \& Fuson, 1999). They need time to think about the problem presented (Fuchs, Fuchs, Hamlett, \& Appleton, 2002; Bromley \& Modio, 1997; Jitendra \& Hoff, 1996), connect the problem to schemas that already exist, predict what will occur, and justify that prediction before attempting to solve the problem (Fuchs, Fuchs, Hamlett, \& Appleton, 2002; NCTM, 2000; Bromley \& Modio, 1997; Jitendra \& Hoff). Much can be learned when students are discussing, revising, and defending their process. It is through these types of activities that teachers can assess students' mathematical understandings and develop appropriate learning opportunities (Bratina \& Lipkin, 2003; Cornell, 1999; Fuchs, Fuchs, Hamlett, \& Karns, 1998; Kazemi, 1998). However, this type of activity is not what you find in traditional mathematics classrooms, it is not the type of instruction that many teachers were taught to use and therefore can be intimidating to implement (Quinn \& Wilson, 1997; Smith, 1996; Gregg, 1995; Cuban, 1993; Borko, Eisenhart, Brown, Underhill, Jones, \& Agard, 1992; Putnam, Heaton, Prawat, \& Remilliard, 1992; Wood, Cobb, \& Yackel, 1991). 


\section{Traveling Together}

Vygotsky’s sociocultural theory (Kazemi \& Stipek, 2001; Pugalee, 2001; Steele, 2001; Battista, 1999; Jaramillo, 1996; Englert, 1992) provides us with a theoretical framework describing how these types of social interactions can strengthen students’ mathematical understandings. Social experiences shape students' thinking and therefore play a vital role in the learning process (Kazemi \& Stipek, 2001; Steele, 2001; Battista, 1999; Jaramillo, 1996; Englert, 1992). Individuals interact with one another in social situations to negotiate meaning (Baxter, Woodward, \& Olson, 2001; Kazemi \& Stipek, 2001; Steele, 2001; Battista, 1999; Jaramillo, 1996). It is through these social interactions that students gain a deeper understanding of concepts while developing their own interpretive meaning and forming mathematical justifications (Millard, Oaks, \& Sanders, 2002; Baxter, Woodward, \& Olson, 2001; Steele, 2001). By providing structured opportunities that will capitalize on these interactions we can create an atmosphere in mathematics that will encourage discourse (McGuire \& Harshman, 2002; Bernero, 2000; Rasmussen, 1999). Important themes in Vygotsky’s writings are discussed in Forman and Cazden (1994):

He is not simply claiming that social interaction leads to the development of the child's abilities in problem-solving, memory, etc.; rather, he is saying that the very means (especially speech) used in social interactions are taken over by the individual child and internalized. Thus, Vygotsky is making a very strong statement here about internalization and the social foundations of cognition (Wertsch, 1981, p. 146). 
This theoretical framework, when used in instruction, has students sharing their ideas and explaining their thinking (Steele, 2001; Englert, 1992). Whitin and Whitin (2003) concluded that “one student's idea can become an invitation for another child to modify and extend the discussion” (p.145). Pugalee (2001) states, “This communication can take the form of various oral and written endeavors; but the primary goal remains to enhance the mathematical reasoning of students” (p. 236).

Exploring a New Route - Using Mathematical Language

To effectively reason and communicate mathematical understandings, students must acquire and use the language of mathematics (Adams, 2003; Bratina \& Lipkin, 2003; Draper, 2002; Ediger, 2000; Monroe \& Orme, 2002; Pugalee, 2001; Burns \& Silbey, 2000; Pimm, 1987). While language plays an important role in understanding mathematical concepts, it is often absent in traditional approaches to teaching mathematics (Adams, 2003; Draper, 2002; McGuire \& Harshman, 2002; Monroe \& Orme 2002; Blessman \& Myszczak, 2001; Smith, 1996; Vacca \& Vacca, 1996; O’Brien, Stewart, \& Moje, 1995). Mathematics instruction should encourage communication by providing activities for learning and using the language (Adams, 2003; Bratina \& Lipkin, 2003; Draper, 2002; McGuire \& Harshman, 2002; Monroe \& Orme, 2002; Pugalee, 2001; Burns \& Silbey, 2000; Smith, 1996; Gaustad \& Messenheimer-Young, 1991; NCTM, 1991, 1989). “When we pass up the opportunities to focus children’s attention on mathematics as a language and not just as something we do, children may miss the 
underlying concepts of mathematics that would enhance and reinforce their understanding” (Adams, 2003, p.787).

In the literacy classroom students are encouraged to access their prior knowledge to predict, to question whether what they are reading is making sense, and to draw conclusions based on what they have learned (Cooper, 2000; Taberski, 2000; Keene \& Zimmerman, 1997; Fountas \& Pinnell, 1996). However, it is these same ideas which can be used to encourage mathematical thinking and understanding (Bratina \& Lipkin, 2003; Draper, 2002; Manzo, Manzo, \& Estes, 2001; NCTM, 2000; Carpenter \& Lehrer, 1999; Ruddell, 1997; Dynak, 1997). Bratina \& Lipkin (2003) discuss how teachers must consciously plan experiences that improve students' critical reading skills in order to improve their ability to communicate in mathematics. Included in their recommendations for these experiences is, "Creating instances for students to experience words in different contexts” (p. 5). It has been suggested that teachers should emphasize the differences between mathematical language and everyday language and provide time to practice using mathematical language (Adams, 2003; Bratina \& Lipkin, 2003; Billmeyer \& Barton, 1998). Practices which encourage the use of language in mathematics could be incorporated in the mathematics classroom through cooperative learning activities and through verbal or written discourse (Adams, 2003; Cornell, 1999; Fuchs, Fuchs, Hamlett, \& Karns, 1998; Kazemi, 1998).

Alternative Routes for Mathematical Communication: Mathematical Discussions

School is a setting where students frequently search for the opportunity to socialize with their peers. When you walk into a classroom you will often hear the 
teacher saying, “I can’t get started until you are all quiet” or "If you would like to say something, please raise your hand.” If we take the students yearning to socialize and create an environment that structures their dialogue, we can add a unique dimension to the mathematics program.

Through small group discussions that focus on mathematical concepts, students can revise their thoughts, make connections, and prepare justifications (Millard, Oaks, \& Sanders, 2002; Baxter, Woodward, \& Olson, 2001; Steele, 2001; Burns \& Silbey, 2000; Pimm, 1987), thus building their conceptual knowledge (Owens \& Fuchs, 2002; Huggins \& Maiste, 1999; Goldman \& Hasselbring, 1997). While teachers strive to include all students in instructional activities, some students choose to disengage themselves from certain activities for various reasons. Research conducted by Baxter, Woodward, \& Olson (2001) indicates that academically low-achieving students typically remain passive in whole-class discussions. The researchers found that when these students participate, their answers tend to be simple responses or “I don’t know.” By providing students the opportunity to discuss with a peer or a small group their mathematical ideas and questions, teachers allow them to practice what they will say in the class discussion as well as prepare them to write justifications (Baxter, Woodward, \& Olson, 2001). It has been found that this practice helps many students feel more comfortable and secure in what they will be saying (Owens \& Fuchs, 2002; Baxter, Woodward, \& Olson, 2001; Wickett, 2000; Thornton \& Langrall, 1997; Pimm, 1987). Thus, more students may offer their answers and justifications in class discussions instead of deferring the question to someone they think is smart (Rasmussen, 1999). 
There are many cooperative learning techniques which engage all students in verbal discourse (McGuire \& Harshman, 2002; Bernero, 2000; Bromley \& Modio, 1997; Wood \& Algozzine, 1997; Creed, 1996; Kagan, 1990). A cooperative learning structure that can assist in reaching this goal is known as "think-pair-share" (Candl, 2004; Jones, 2002; Creed, 1996; Kagan, 1990). Developed by Frank Lyman in 1981 (Jones, 2002), this structure emphasizes what students are to be doing at each stage. The first stage, "think" requires the teacher to provoke students' thinking with a prompt. The students take a few moments to simply think about what has been presented. The second stage, "pair" requires students to pair with a partner and talk about their thoughts and compare written or mental notes. The final stage, "share" requires the students to share their thinking with a group of students (Jones, 2002; Kagan, 1990). Whitin and Whitin (2003) found that conversations in the mathematics classroom provided a forum for assessing the children's knowledge of concepts and strategies. They also discovered that it gave the teachers a chance to reflect on their own teaching. Reflecting on personal teaching habits is not easy. Teachers tend to examine the students actions and reactions instead of their own. However, if the goal is to see a change in the student's learning, a change in the teacher's actions may need to occur first.

Alternative Routes for Mathematical Communication: Mathematical Writing

Another means for social interaction is through writing (Huggins \& Maiste, 1999; Powell, 1997; Williams \& Baxter, 1996). In my classroom I find detailed notes that students write to one another relaying their thoughts and ideas. This type of writing is informal and non-threatening. There is no thought of grammar or spelling, the focus is to 
put their thoughts on paper. As teachers we often try to limit these interactions as to not disrupt our teaching. However, we can use these types of interactions to enrich students' mathematical learning. As one of the original “three R's” writing was thought of as a skill that simply needed to be taught. However, writing has proven to have a positive effect on students’ mathematical understandings when it is used as a tool to aid learning (Millard, Oaks, \& Sanders, 2002; McIntosh \& Draper, 2001; Woodward, Monroe, \& Baxter, 2001; Jurdak \& Abu Zein, 1998; Quinn \& Wilson, 1997; Winograd \& Higgins, 1994-5; Fulwiler, 1987). Writing has been shown to increase mathematical learning (Crespo, 2003; Millard, Oaks, \& Sanders, 2002; Burns \& Silbey, 2000; NCTM, 2000; Burns, 1995; Dusterhoff, 1995; Winograd \& Higgins, 1994-5; Fortescue, 1994; Abel \& Abel, 1988). As students write in mathematics they have the opportunity to clarify, confirm and extend their mathematical thinking and understandings (Crespo, 2003; Millard, Oaks, \& Sanders, 2002; Albert \& Antos, 2000; Huggins \& Maiste, 1999; Dusterhoff, 1995; Winograd \& Higgins, 1994-5; Fortescue, 1994). Dialogue journaling is a means for reflecting and writing in mathematics while communicating with others. A dialogue journal is a written conversation between two writers (Perry, 2001; McGrath, 1992; Gaustad \& Messenheimer-Young, 1991; Bode, 1989) requiring both to use metacognitive reflections on their learning process (Goldsby \& Cozza, 2002). The feedback provided in a dialogue journal serves as a mechanism for vocabulary development, for explaining students' mathematical thinking, and for understanding the metacognitive process in which the students are involved (Goldsby \& Cozza, 2002; Perry, 2001; McGrath, 1992; Gaustad \& Messenheimer-Young, 1991; Bode, 1989). The practice of writing thoughts 
and justifications and responding to others may enhance the students' ability to independently respond to challenges. When peers provide feedback and support, computational ability in low achievers' improves (Baker, Gersten, \& Lee, 2002). Although this research focused on computational skills, the idea that students can effect the performance of their peers is encouraging. However, studies examining the effect dialogue journals have on students' writing mathematical justifications could not be located. Laura Candl (2004), a classroom teacher, notes a variation in the think-pairshare structure. In her variation students write down their ideas before discussing them with their partner, this creates a "think-write-pair-share" structure and increases individual accountability.

Writing also helps teachers assess student learning, and this analysis help teachers plan future instruction (McIntosh \& Draper, 2001; Jurdak \& Abu Zein, 1998; Quinn \& Wilson, 1997; Burns, 1995; Dusterhoff, 1995; Winograd and Higgins, 1995; Gaustad \& Messenheimer-Young, 1991). This finding is critical as teachers attempt to discover their students' mathematical thinking.

A successful teacher learns from feedback that is given in such writings. I might not understand how a student did a problem until I see the explanation. If I am still unsure that the student is clear in the process, I will ask the student to explain to the class. This helps clarify for the students and for me what they do understand. The "explaining” process is not a "challenging" of the methods but an opportunity to help others see what they did (Goldsby \& Cozza, 2002, p. 519). 
Armed with this information, the teacher is able to adjust her questioning and instruction to ensure students’ instructional needs are met (Goldsby \& Cozza, 2002; Sharp \& Adams, 2002; Cobb, Stephan, McClain, \& Gravemeijer, 2001; Cobb, 1999). In an effort to help her students better understand math concepts, teacher Chelsea Fortescue (1994) collaborated with a language arts teacher to engage students in mathematical writing. Through the use of journal writing, Fortescue realized that her students required more whole group modeling of both oral and written language. By providing this support Fortescue (1994) then discovered that "in writing about math problems or activities, students become familiar with analytical writing while gaining and displaying a deeper understanding of the math concepts” (p. 522).

While these types of activities are important for all types of learners, for students with learning disabilities these interactions can build the bridge that connects their mathematical understandings (Woodward \& Montague, 2002; Woodward, Monroe \& Baxter, 2001; Woodward \& Baxter, 1997). Winograd \& Higgins (1994-5) contend that, “... elementary school students often approach school mathematics problems impulsively, attending to surface features of the problem situation in order to decide what action to take” (p. 316). All students, including those students with learning disabilities, need to be engaged and supported in metacognitive activities which allow them to think about what they know about the problem (Woodward \& Montague, 2002; Woodward, Monroe \& Baxter, 2001; Woodward \& Baxter, 1997). Through writing, students can write or draw initial thoughts and questions pertaining to the problem. As stated earlier, an activity promoting metacognition and peer response is dialogue journaling. For 
students with learning disabilities, peer models and collaborative groups can be beneficial. These interactions allow them to hear strategies of other students that they may not hear if they are in a remedial environment (Baxter, Woodward, Olson, 2001; Owen \& Fuchs, 2002; Woodward, Monroe \& Baxter, 2001; Mercer \& Lane, 1996). Participating in this exchange of ideas helps students make connections in their mathematical learning and put into words what they are thinking. In addition, teachers can discover misconceptions students have and gaps in their understandings. These types of activities also provide teachers with the opportunity to differentiate between what students truly understand and what they have merely memorized. Armed with this information, teachers can make instructional modifications and accommodations so that all students have an equal chance of understanding the concepts.

\section{A New Set of Directions}

As discussed, expectations in regard to what students should know and be able to do in mathematics have changed (NCTM, 2000, 1998, 1995, 1989). Students are still required to demonstrate their ability to compute in mathematics. However, being able to complete a specific procedure is no longer sufficient. Students now need to demonstrate their ability to effectively communicate their mathematical understandings and justifications (NCTM, 2000). As the literature presented indicates, students benefit from social interaction with peers in the classroom (Baxter, Woodward, \& Olson, 2001; Jaramillo, 1996; Englert, 1992). These social interactions can occur in writing (Goldsby \& Cozza, 2002; Gaustad \& Messenheimer-Young, 1991; Bode, 1989) or in oral discussions (Millard, Oaks, \& Sanders, 2002; Baxter, Woodward, \& Olson, 2001; Steele, 
2001; Burns \& Silbey, 2000; Pimm, 1987). These activities assist in satisfying the Reasoning \& Proof and Communication Standards described by the National Council of Teachers of Mathematics (NCTM, 2000). However, additional studies are needed to provide support for specific instructional practices. In this study, I analyzed the written and oral dialogues of individual students. This analysis provided valuable information regarding the instructional needs of the students and served as an aid for planning future activities and experiences. 


\section{Chapter 3:}

Methodology: Taking the Scenic Route

The Principles and Standards for School Mathematics (NCTM, 2000) emphasize the importance of reasoning and communicating mathematical understandings. In addition to the Principles and Standards for School Mathematics (PSSM), the expectations on the Maryland School Assessment (MSA) have confirmed the need for on-going research into the development of students' mathematical understandings and their ability to communicate those understandings. This study was conducted in direct response to this need and addressed the following questions:

1. What is the effect of dialogue journals and oral discussions on students' mathematical writing?

2. How are students mathematical understandings reflected in their written and oral discussions?

This study took place at River View Elementary School, a small rural elementary school in Western Maryland. River View Elementary is a Title I school having $62.4 \%$ of 
students receiving free or reduced meals. Most River View community members attended River View Elementary, have lived in the community most of their lives, and feel ownership in the school. In the past two years 95\% of parents were involved in parent teacher conferences. However, while parents may have expressed interest in their children's progress, there was little parental volunteer involvement without specific personal requests from the school. River View Elementary serves approximately 90 students from kindergarten through grade five. At River View Elementary there are seven full time teachers, one assistant, one teaching principal, and a secretary who serves as the librarian. A nurse and counselor each visit the school approximately 3 hours per week. My study involved the grade four and grade five students who were in a combined classroom. These students shared a teacher in mathematics, science, social studies, and resource classes. In this inclusive classroom there were 16 grade four students and 9 grade five students. Two of the fourth grade students had Individual Educational Plans (IEP) with specific goals in mathematics. All 25 students were invited to participate in this study, but two declined the invitation.

\section{Changing Lanes}

In turning the corner, I challenged myself to change my practice. In doing so I took a critical look at effective techniques for helping my students gain an understanding of mathematics as well as writing mathematical justifications (Woodward, Monroe \& Baxter, 2001; Powell, 1997; Cai \& Jakabcsin, 1996). This required a change in my interactions with the students as well as the way in which my students interacted with each other. The teaching experiment (Polaki, 2002; Cobb, Stephan, McCain \& 
Gravemeijer, 2001) provided both a teaching methodology and a research framework for conducting a rigorous examination of both practice and students’ understanding. According to Cobb (2000, cited in Polaki, 2002), “A teaching experiment is a conceptual tool for documenting changes in students mathematical thinking patterns over time” (p. 286). It required me to analyze my students’ responses, and make inferences regarding their instructional needs, and it provided a basis for creating learning opportunities to meet their needs.

\section{Toll Road: Collecting Baseline Data}

The Maryland School Assessment (MSA) requires students to demonstrate their mathematical understandings through written justifications on Brief Constructed Response (BCR) items. The BCR item is a two part mathematics problem. The first part of the BCR requires students to solve a mathematics problem. The second part requires students to justify their answer and describe how they solved the problem (Appendix A). Since September 2003, BCR items had been administered and scored each month. A total of 19 BCR items (representative of each month) were saved and kept in a file cabinet at the school. Baseline data consisted of one BCR randomly chosen from each month for a total of seven BCR items (September through March). These BCR items were re-scored by Mr. Smith, a colleague in Brown County. Using the Maryland School Assessment Brief Constructed Response Rubric (Appendix B) students could receive a 0, 1, or 2, 2 being the highest.

\section{Using a Teaching Experiment as a Roadmap}

The teaching experiment permitted me to develop sequences of instructional 
activities and analyze students’ mathematical learning as it occurred (Cobb, Stephan, McClain, \& Gavemeijer, 2001; Cobb, 1999). In this study I followed the basic developmental research model (Polaki, 2002; Cobb, Stephan, McClain, \& Gavemeijer, 2001) consisting of two phases: instructional design and classroom-based analysis (Figure 1).

Instructional
Design

Figure 1 The instructional design research model

Instructional design is the development and sequence of learning activities with conjectures about student's responses and the support they will likely need during instruction. These conjectures are tentative as they are tested and modified during the next teaching episode (Sharp \& Adams, 2002; Cobb, Stephan, McClain, \& Gavemeijer 2001; Cobb, 1999). The classroom-based analysis involved the examination of students' written work, oral dialogues, and my field notes to draw inferences about their mathematical understandings and their ability to communicate their understandings (Cobb, Stephan, McClain, \& Gavemeijer, 2001). This analysis served as a basis for subsequent instructional activities. 


\section{Exit Ramp: Teaching Episodes}

Prior to each teaching episode, students were assigned a partner using the established classroom practice of drawing “sticks”, each of which had one name written on it. Each task represented mathematical content previously explored in the classroom. The content standard addressed in the task corresponded to the grade four and grade five portion of the Mathematics Voluntary State Curriculum used to guide classroom instruction.

To investigate the ways in which students' mathematical understandings were reflected in their written and oral discussions, participants followed a multi-step process.

1. Participants were given a task in the form of a mathematical word problem and instructed to individually reflect on the task. They wrote questions, comments, and thoughts on their dialogue journaling paper. Through this process of writing, students had the opportunity to begin thinking of what they knew about the task presented and what they needed to find out.

2. Participants exchanged journaling papers with their partners and responded to their partner's questions, comments, and thoughts. This exchange process continued until no new information was shared.

3. Participants engaged in oral dialogue with a small group.They discussed unanswered questions and their mathematical thinking in regard to the task (audiotape recordings occurred during this step). All participants had the opportunity to discuss the strategy they planned and justify their choice. It was 
during this small group discussion that participants began to share their point of view providing support, or they changed their minds after hearing their peers' thoughts.

4. Participants completed the task independently and justified their answer in writing. Dialogue journaling was repeated.

5. The class engaged in an oral discussion, sharing answers and justifications.

In planning for the next teaching episode, I reviewed students’ dialogue journaling papers and my recording sheets. In addition to this analysis, I relied on my intuition to infer how the participants' mathematical understandings were reflected in their oral discussions and in their writing (classroom-based analysis). The use of informed intuition is a common practice among educators (Perry, 2001) as students’ instructional needs are not always communicated directly. If the conclusion was made that the participants did not understand the mathematical concept, then an activity which explored that concept was planned. Following this instructional design model enabled me to plan instructional activities that met the needs of the students.

A total of 17 episodes involving the dialogue journals and oral discussions were conducted.

Scenic Overlook: Data Collection and Analysis

A variety of data sources including initial and post BCR items, field notes, and writing samples were used in seeking answers to the questions: 
1. What is the effect of dialogue journals and oral discussions on students' mathematical writing?

2. How are students mathematical understandings reflected in their written and oral discussions?

Throughout the teaching experiment I wrote field notes consisting of my observations, impressions, observation analysis, and my immediate reflection of the experience.

An audiotape recording was made of the small group and whole group discussions and later transcribed verbatim. I reviewed the transcriptions or listened to the tapes noting students’ inflections, pauses, and specific comments.

Several data sources were used to triangulate the data (Patton, 2002). These data included: (a) student dialogue journals, (b) audiotape recordings of group discussions, (c) my field notes, (d) additional student mathematical writing, and (e) BCR items.

Following the conclusion of the teaching experiment, I conducted an in-depth analysis of the data. This analysis occurred by working through the data chronologically episode by episode (Cobb, Stephan, McClain, \& Gavemeijer, 2001). I used inductive analysis letting categories, themes, and patterns emerge from the students written and oral dialogues (Perry, 2001). Initially, I analyzed the data looking for evidence that students were thinking strategically and that they were able to communicate their mathematical understandings. This initial procedure assisted in identifying categories, themes, and patterns (Perry, 2001).

The categories, themes, and patterns gathered from student responses to the BCR 
items, dialogue journal entries, contributions to oral discussions, field notes, and journal entries provided insight into the development of students' mathematical understandings and their ability to communicate their understandings in writing. 
Chapter 4

Our Journey

Teachers who inspire realize there will always be rocks on the road ahead of us. They will be stumbling blocks or stepping stones; it all depends on how we use them.

-Author Unknown (National Staff Development Council, 2000)

My Travel Companions

All students venture into the classroom with their own personalities and past experiences. The combination of students contributes to the class atmosphere and helps set the pace for the school year. Certain combinations of students allow a teacher to explore new paths with little disruption, while other combinations create road blocks that get in the way of academic learning. The personalities and experiences of the 25 students I worked with were very diverse. This combination created a class atmosphere that hindered, and at times prevented, the class from venturing down new paths and exploring new ideas using alternative strategies. This class was composed of students who had needs that often extended beyond what the school could directly address. 
As I stood before the class, I thought about their individual situations and the road blocks before them. I looked at the newest addition to the class, a shy fifth grade girl named Joy. Joy arrived at the beginning of the school year as a homeless student. She and her mother traveled throughout the school year to various living spaces including a domestic violence shelter. She had previously been retained and when she enrolled was a nonreader. She lacked self confidence and often hid her face by combing her hair forward. Two rows in front of Joy sat Cindy. Cindy was a fifth grade girl who was visited frequently by Social Services, who took medication for Attention Deficit Disorder, and who had a 504 Plan. She exerted a tough girl image with most of the kids. She would work really hard one day and on the next was one of the most belligerent kids you would ever meet.

In the back row, near the teacher's desk, sat Cory, a fifth grade boy. Cory was one of the brightest kids in class and had great potential but lacked self control and discipline. He lived with his mom and her current boyfriend who remained drunk most of the time and who did not provide adequate supervision to the boy. This lack of supervision allowed Cory to get into mischief, and he was put on probation by the Department of Juvenile Justice in March. Immediately following these events he refused to work and was extremely disruptive. However, he came to school each day and when he did miss the bus would call the school and ask for someone to go and get him (which we did). Cooper, Kevin, Dylan, and David were fourth grade boys diagnosed with Attention Deficit Disorder with Hyperactivity (ADHD) and taking medication. Cooper and Dylan had Individual Education Programs (IEP) and Cooper was diagnosed with a behavior 
disorder. Kevin had a 504 Plan, and David was on probation with Juvenile Justice and living in a home where domestic violence occurred frequently. Sixteen of the students in this class were living in two parent homes; nine were from broken homes. Four families were active in the school's Parent Teacher Organization (PTO). Out of the 25 students, Samantha, Sarah, Alexandra, Ella, Micky, and one of the students not participating in the study, were viewed by their teachers as "good students" due to their willingness to participate and their ability to get along with their classmates.

As I stood before the class, with their histories and current situations ringing in my mind, I thought of the courage it took for many of them to show up at school. Academics were not a priority for the majority of these students. This was a group with a reputation of being difficult to teach, but these students had a lot to teach me. If I wanted to see a change in their academics, I had to look beyond their challenges and make the initial move in a new direction. I was reminded of the quote by Dr. John Maxwell, "If we keep on doing what we've always done we're going to keep on getting what we've always gotten” (NSDC, 2000). It was time to travel a new path with these students.

\section{Life is a daring adventure or it is nothing. \\ -Helen Keller (NSDC, 2000)}

\section{Examining the Map}

I engaged the students in the process of dialogue journaling (Perry, 2001; McGrath, 1992; Gaustad, \& Messenheimer-Young, 1991; Bode, 1989). Dialogue journaling is an instructional technique designed to encourage students to write and discuss their thoughts, questions, and mathematical ideas about a problem before 
attempting to solve the problem as well as convince a partner that their solution to a problem is correct. This technique provided students the opportunity to think about what they knew about the problem and what they did not understand about the problem before attempting to solve it. To investigate students' mathematical thinking participants were instructed to follow a multi-step process.

1. Participants were given a task in the form of a mathematical word problem and instructed to individually reflect on the task. They could have written questions, comments, and thoughts on their dialogue journaling paper. Through this process of writing, students had the opportunity to begin thinking of what they knew about the task presented and what they needed to find out.

2. Participants exchanged journaling papers with their partners and responded to their partner's questions, comments, and thoughts. This exchange process continued until no new information was shared.

3. Participants engaged in oral dialogue with a small group of students. They discussed unanswered questions and their mathematical thinking in regard to the task (audiotape recordings occurred during this step). All participants had the opportunity to discuss the strategy they used and began justifying their choice. It was during this small group discussion that participants could begin to share their point of view providing support or they might change their minds after hearing their peers’ thoughts.

4. Participants completed the task independently and justified their 
answer in writing. The dialogue journaling process continued.

5. Participants engaged in an oral discussion as a class. They shared answers and justifications.

I kept field notes consisting of my observations, impressions, observation analysis, and my immediate reflection of the experience. An audiotape recording was made of small group and whole group discussions and transcribed verbatim. I listened to the transcriptions noting students' inflections, pauses, and specific comments. From these data I was able to plan my next teaching episode and examine each student’s progress. Follow me on our learning journey as I describe what occurred in our classroom. "Just tell me what to do!"

The students' first reactions to the activity were as diverse as their personalities. While some embraced the activity, others seemed intimidated to try something so different:

Julie looked really mad. She continued to stare at me, mouthing 'help me' and making huffing noises. Mitch refused to exchange papers with his partner. Samantha raised her hand, asking if she should add or subtract. One student put his head inside his desk and decorated his body with his pen while Cooper laughed at him. Kristen looked on her neighbor's paper, brushed her hair back with her hand and made ahhhhh noises. Rachel, Carol, and Ella seemed to be taking this very seriously. They wrote like crazy and told their talking classmates to be quiet. (Session 1) 
As the first activity came to an end I felt both overwhelmed and excited. There was only one way to go - up. As I reviewed all the data collected this first day and spoke to their past teachers, I realized these students had not been given many opportunities to work together. I was told that the dynamics of the group made controlling group activities a challenge. When questioned, one teacher responded that she “couldn't stand the noise and felt like she had no control.” If noise was going to be the biggest problem I would be okay. Noise would not bother me as long as the kids were learning. I believed that this type of cooperative learning activity would benefit the students. Cooperative learning activities have been shown to generate more interest in math and improve students academically, socially, and in self-esteem (Baxter, Woodward, Voorhies, Wong, 2002; Bernero, 2000; Wood \& Algozzine, 1997; Nattiv, 1994). I also believed that the students would only become better at working together if given the opportunity to practice. Beginning Trends: Math was...

As my students began to engage in the dialogue journaling process, several themes emerged. They had misconceptions about the process of mathematics and a skewed perception of mathematical connections. To many of my students math was simply computing. When presented with a problem students immediately began to calculate a numerical answer, skipping the discussion parts of the process. These attempts seemed impulsive, and no justification or reasoning accompanied the answer. A typical written dialogue between two students demonstrated this trend (Session 1).

Samantha: Do I add or - ?

Ricky: You do add on the problem. 
Samantha: What do we add?

Ricky: You add 1.252 times for 7 days.

Unsure of what to do, Samantha asked her partner Ricky what type of computation she should perform. Samantha accepted Ricky’s suggestion without any justification or questioning and started computing. Students would often change their math procedure if their partner suggested a different way of solving the problem, or if they were unsure of what to do they accepted their partners' suggestion without a reasonable explanation for the suggestion. Amit \& Fried (2002) found that students create a web of authority in the classroom which consists of both the teacher and peers. This authority refers to those who, in the student's mind, have the most knowledge regarding mathematics. As the previous example illustrates, Samantha listened to Ricky’s suggestion without any mathematical justification. To Samantha, he was more of a mathematical authority.

To many of my students, math was a silent activity. During the discussion time there was talking but essentially no discussion. Instead, this time was used by the students as a time for round-robin sharing (Maloch, 2002). It became an opportunity for group members to give their answer and read what they wrote. The following discussion took place during Session 5. Notice the ways in which students shared their answers.

Aaron - You would add sixty minutes then twenty then forty five then thirty and fifteen minutes altogether and you would get ummmm two hours and ten minutes.

Julie - Now it will be Kevin. 
Kevin - You you you would solve the problem by adding, (look at your paper Cooper, your paper not mine). You would need to add the one hour twenty minutes plus twenty minutes plus forty five plus one hour plus fifteen minutes equals an hour and twenty minutes.

Julie - Now it will be Micky.

Michael - To get the answer you would add one hour twenty minutes, forty five minutes, thirty minutes and fifteen minutes to get your answer.

Julie - Now it will be Eddie.

Eddie -You would add. You would add a half hour and one for one hour twenty minutes and forty five and fifteen. You would, you'd get eleven then five plus five plus one, add the one and then three plus two plus four plus two would equal one hour and forty six minutes.

Julie - Now will be Erica.

Erica - I wrote to Julie I think you should add one hour and twenty minutes plus thirty minutes plus fifteen minutes and see what you get. Then I put... ok that sounds alright.

Julie - Okay it will be Julie me, I put Dear Erica we should add the numbers is one hour twenty minutes and then add forty five and then that was it and she said that's ok.

Although the answers which were shared were not always correct, each answer was accepted by the group. It was unclear whether or not students understood the mathematical concepts in the problem. Something stopped them from engaging in 
productive discussions. They simply did not know how to talk to one another about their mathematical thoughts. Were the barriers related to their unfamiliarity with using language as a tool to understand math? Was it that they did not understand the concepts well enough to discuss them?

Changes in Trends: Watching Mathematics Become More To Students

Using a teaching experiment (Cobb, Stephan, McClain, \& Gavemeijer, 2001; Cobb, 1999) enabled me to make instructional decisions based on the data collected. In an attempt to encourage my students to think before computing, in Session 9 I decided to include the question, "How do you think the problem should be solved?” (Appendix C). Students answered the question with responses such as: “Keep dividing by 2 ” (Carol \& Erica, Session 9); “Draw a picture” (Ricky \& Joy, Session 9); “You can draw a picture or you can keep dividing by 2 or try it out w/ a real ball” (Dylan, Session 9). While they still lacked justification, they were beginning to show signs of planning. To many of my students, math was becoming strategic.

To help support written justifications, in the next activity, I directed students to address their partner's chosen strategy by answering the question, "Will the strategy described work? Why or why not?” For the most part, students responded to these cues with reasonable direction for their partners. "Your strategy will not work you still have halfs to dill with" (Cory, Session 10); "You should put the halfs together to make a 1 hole instead of not counting them at all” (Joy, Session 10). Students were struggling to make sense out of the procedure they were following, perhaps a result of their lack of conceptual understanding. Although the focus of the dialogue remained on computational 
procedures, some students began to question the advice given. Additionally, they began to demand reasoning from their partners. "I don't get what you wrote tell me more" (Rachel, Session 10). To many of my students, math was becoming sensible. They began to search for these reasonable explanations in both their written and verbal discussions.

Interestingly, some students needed different kinds of support in their search for reason. For example, some began having private discussions. I noticed that Joy and Micky whispered back and forth. They tried to hide their conversation from me. When I walked near them they stopped and they continued to watch me as they talked. (They think I don't "see” them because I'm not looking straight at them). When I made eye contact with Joy during part of their conversation I winked and shook my head - she winked back. (She is really coming out of her shell.) They continued to whisper and then drew pictures to solve the problem. This may be the first time she actually completed an activity. (Session 9)

Another student used a strategy I’ll refer to as “self talk.” I observed Julie (Session 14) mumbling and verbally correcting herself. She knew when her ideas did not make sense and continued to talk her way through the problem.

It is important to note that I did not redirect these students but instead allowed them the opportunity to use the process in ways that fit their needs. I was proud that the students were now using the process to forge their way mathematically. However, at the 
same time I was offering support to get my students to initially think about the problem, I had to address their inability or unwillingness to engage in verbal discussions.

During the teaching experiment I found that support was needed for both written and oral dialogue. With my guidance, the students moved beyond round robin sharing. During small group discussions, the discourse further deepened their mathematical thinking. They became better at verbally sharing their mathematical understandings, asking questions of one another, and explaining their ideas (Session 15):

Sarah - The way I got it was, um, at first I thought it was fifty cents cause half of a dollar is fifty and, but then Alexandra told me it was a dollar fifty and um, and not just a dollar and then I figured it must be seventy-five cause um, what I wrote down was 'it must be seventy-five cause a dollar fifty is five um five quarters and Kelsey will get seventy-five percent of the candy bar and her friend will get fifty cents worth, so...

Teacher - Say that again...

Sarah - Kelsey is going to pay seventy-five and her friend is going to pay seventy-five. And when you add seventy-five and seventy-five you get a dollar fifty.

Kristen - I don’t get what I wrote. I wrote her share will probably be fifty or a dollar cause there are probably four pieces so her half would be a dollar.

Teacher - So how much did Kelsey get?

Kristen - Four pieces?

Teacher - Where did you get four pieces? 
Kristen - I don’t know...

Teacher - How many did Kelsey get?

(Silence, then all the kids started talking at once)

Cindy - I think they will have to pay twenty-five cents I mean twenty for each whole one cause twenty for one I mean for three is sixty add twenty is eighty that's eighty cents then add the two halves (silence). Eighty. See that's a dollar then add two that's twenty-five.

Kristen - Maybe they both are twenty-five each and that is fifty cents, put it together and it's a dollar.

(Silence then mumbling)

Teacher - Show me the four and a half pieces.

Kristen - One, two, three, four.

(Mumbling)

Teacher - Let her talk. Think aloud.

Kristen - These are Kelsey’s pieces.

(Kids start talking at once)

Cory - Yeah, if you put...

Alexandra - Cory was telling me that if one, if the squares is twenty five cents then I looked at all of Kelsey’s pieces and put these two together because they would equal a whole and you get a dollar twenty-five so it can’t be..

Cory - No, no, I see it now! 
Teacher - What do you see?

Cory - I um, (mumbling)...she was saying that Kelsey was seventy-five cents but it's not because um, these two halves together and the three whole ones is a dollar, what is the fraction?

This example demonstrates how, with guidance, students began to verbally reason mathematically. They referred to their classmates' presentations and comments. They searched for answers that made sense, and they used discourse to reach a deeper understanding.

Mathematics was no longer randomly choosing a procedure and computing, nor a task where only a few could be successful, or even rote memorization. Math was becoming much more. It was becoming a cognitive activity where students could be strategic, where they could develop sensible explanations, and where they could make connections to their learning.

All of us are shaped by what others expect from us. We live either up to or down to what others believe about us and what we can do. Actually, what other people think of us is frequently more crucial and influential than what we think of ourselves.

\section{Listening to my Students}

As described above, there were general themes that emerged with the class and in the way my students approached mathematics. However, when examining individuals it became clear that each benefited from the experience in a different way. In the next section I highlight four of these students. I chose these students because they each have a different story, their own story. These students took the map given to them and ventured 
down a new road. Though the road was often rocky and full of detours, they arrived having grown from the experience and having taught me a little more about them. Looking Beyond Average: Aaron

Aaron's enrollment at the school was a bit like a revolving door. He had enrolled then transferred to another state several times before returning to our school in the third grade. It was hard not to like Aaron. With a smile that revealed a hint of mischief and his laid back attitude, he was a pleasure to be around. He had many different friends and was the type of kid you could seat next to anyone. During outdoor recess you would find him engaged in a kickball game or on a rainy day playing with LEGOS. He lived with his Mom but spent a great deal of time with his grandparents because of her work schedule. He had his homework completed daily and his grades would indicate average reading and math ability. However, the data collected on Aaron revealed that he had the potential to be more than an average math student. When we first began the dialogue journaling sessions, he seemed to have trouble getting his thoughts in order. He did not seem to understand what the problem was asking him to do, and his feedback to his partners seemed illogical. Evidence gathered throughout the experience indicated that he began to search for strategies that made sense, question ideas, and to explain his thoughts using his math knowledge. Certainly, more then one would expect from an "average” student.

Aaron began the first math problem with the question focusing on computation, “Do you have to divide add subtract or muliti?” (Figure 2). Unsure of what appropriate math procedure to follow, he was stuck. When his partner wrote, You should multiply because you will not get your answer any other way" Aaron made various computation 
attempts on the back of his paper then concluded with the statement, "I added up all the hours and I got 21”.

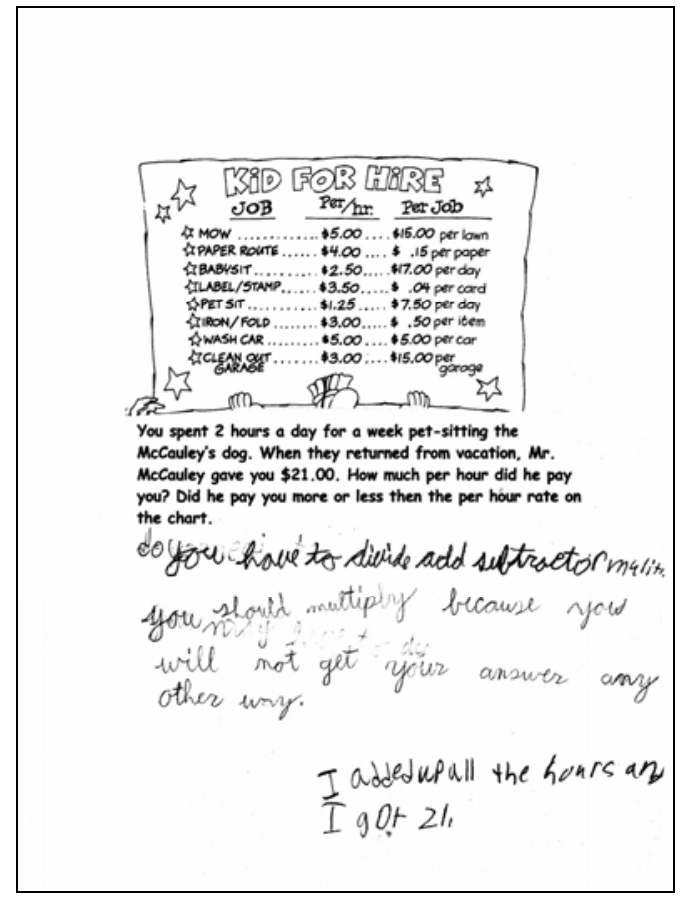

Figure 2 - Aaron's First Attempt

Aaron's focus was on following a mathematical procedure to arrive at an answer, he was computing and guessing. Without a focus on what was sensible, he was unaware that the procedure and answer were incorrect.

In the next several sessions, Aaron at least began offering suggestions for solving the problems even though these suggestions were not always logical. For example, when presented with the prompt in Figure 3, Aaron and his partner wrote,

Aaron - I think per hour because you get 4.00 per job and .15 per hour so we could first try to multiply 43 times 2 hours.

Alexandra- I wasn't sure how to figure it out but that makes sense multiply 43 x 2 hours. 
Aaron - I multiplied the numbers 43 x 42 and got 86 so we now we have to multiply the other numbers.

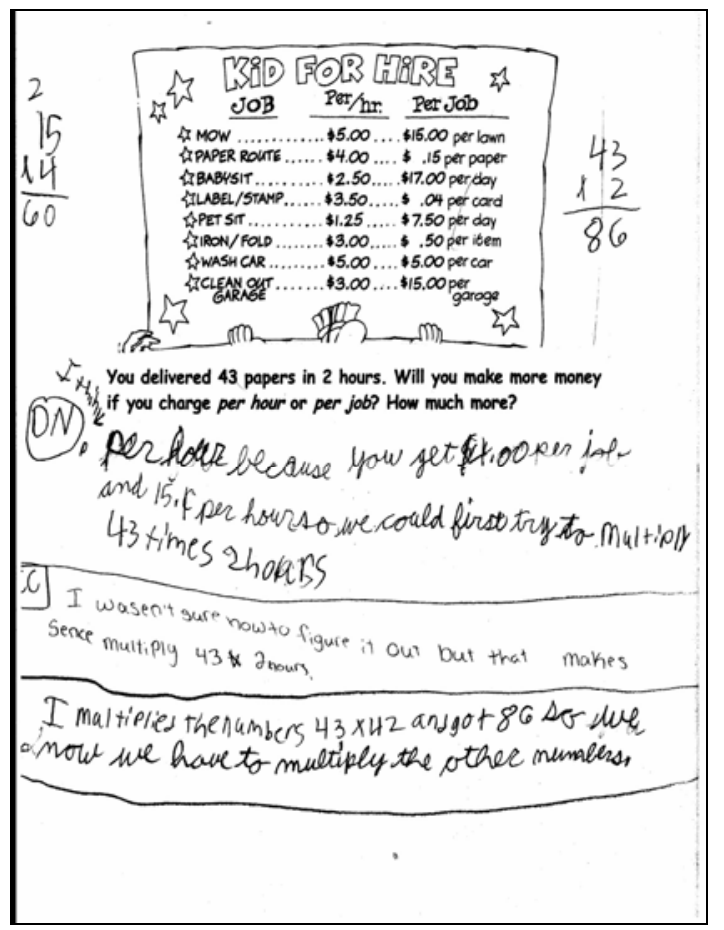

Figure 3 - Aaron Offers Suggestions

This exchange illustrated how both students were confused about what they should do. Once again, the focus was on searching for the "right” numbers to compute to get an answer. However, in later activities, Aaron began questioning his partner’s procedures, seeking one that made sense. "Yeah but how do you know if you got to add?" (Session 5). In addition, Aaron slowly began using different strategies to solve problems. During Session 9 he drew a picture and proposed an alternative strategy (Figure 4). Aaron's focus seemed to be changing; he was expressing interest in more than computing. 


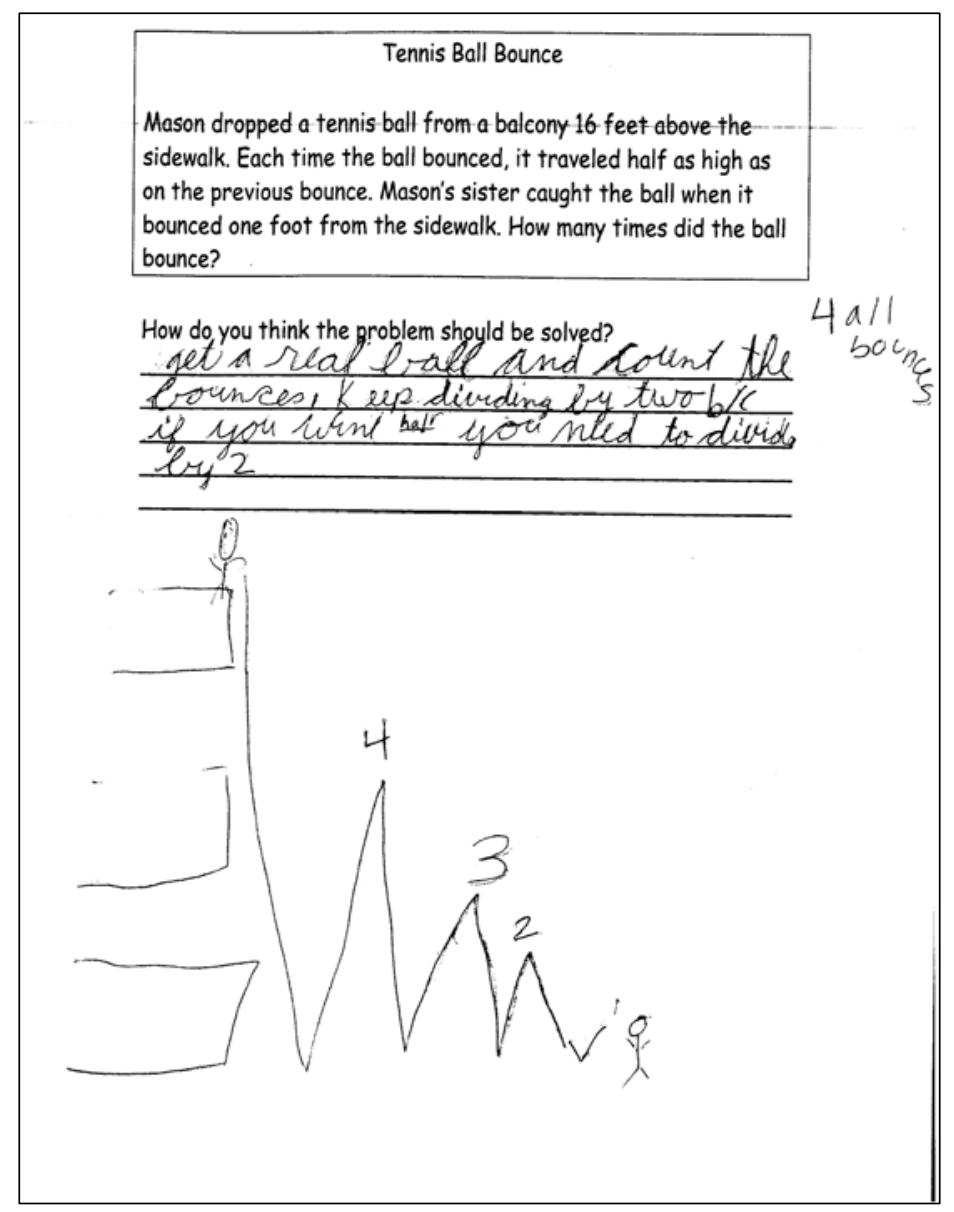

Figure 4 - Aaron’s Attempt to Make Math Strategic

Through this process Aaron, my average student, demonstrated his ability and willingness to think about more than computing when solving a math problem. He searched for strategies and answers that made sense and began explaining and justifying his answers.

\section{A Strong-Willed Child: Mitch}

Mitch was described by classmates and teachers as “annoying.” He spoke out of turn, did not cooperate in group activities, and seemed to strive to be the class clown, inserting inappropriate comments at inopportune times. Often off task, he frequently 
played with items in his desk or passed his time doodling. When redirected, he focused but only for a short amount of time. Although testing for Attention Deficit Disorder was suggested to his parents, they were not willing to explore the possibility. For as much as Mitch liked to talk, I thought he would excel in these activities. However, asking Mitch to discuss a procedure would silence him.

I knew Mitch had strong computation skills, and he was very proud of the fact that he memorized all his multiplication facts to 10. It was difficult to predict Mitch’s response as the activities progressed. On one day he would write to his partner and participate in the discussion, but then the very next day he would refuse to participate and would disrupt the group. I learned his mathematical abilities stretched beyond computation. However, he was insecure with his ability to reason mathematically.

In the initial activities Mitch refused to work with his partner and would not exchange papers. Whenever he did write, it was often only numbers. The same was true during small group discussions when he would give his final answer without participating in any verbal exchange. This did not seem to fit with Mitch’s natural tendencies to talk. By Session 5 Mitch’s involvement in the process increased. When his partner suggested a procedure Mitch responded in writing, “Your ok I think.” (Session 5). During the discussion he shared his procedure and although his explanation was rote and incorrect, at least he participated. "I got I added up one hour twenty minutes, thirty, thirty, fifteen, and fifteen and then I added them all up and got one hour and fifty minutes” (Session 5). In the next several sessions, Mitch wrote illegibly and did not participate in the discussions. During Session 9 there was a change in Mitch’s behavior and willingness to work with a 
partner. A comparison of his written work and my field notes suggested that his participation may have been greater than his actual writing showed. In addition, his illustrations indicated that he had thought of several strategies for solving the problem (Figure 5).

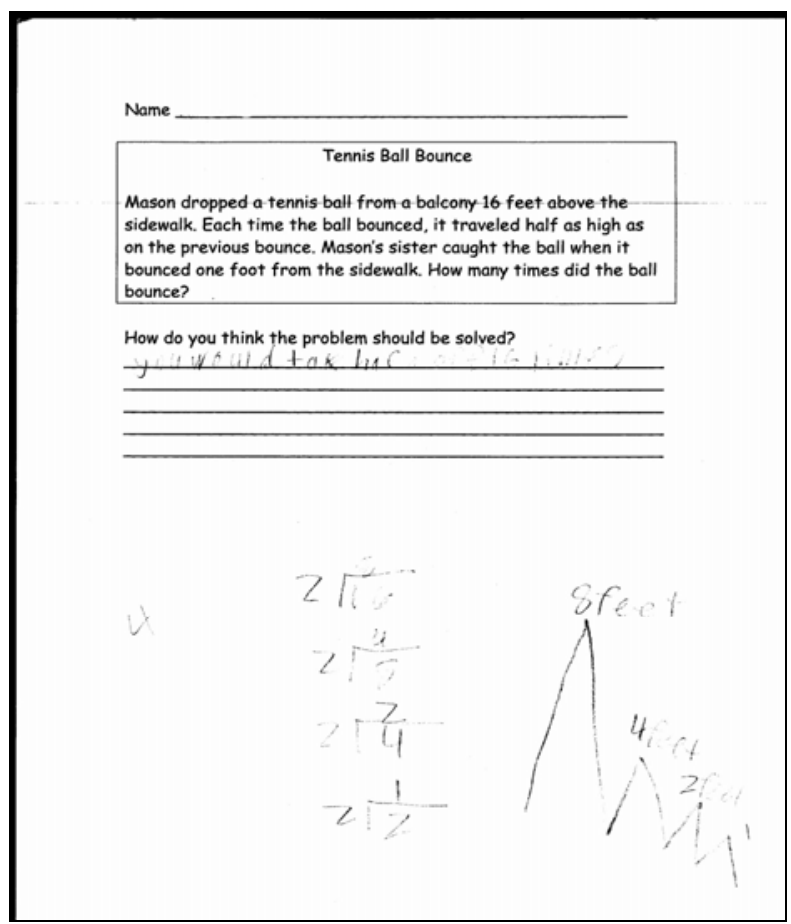

Figure 5 - Mitch’s First Attempt

Mitch wrote how he thought the problem should be solved (it is incorrect).

He was talking with Erica and drew a picture to show how he divided to solve it (it is correct). They were whispering while solving the problem. Mitch was actually being nice to her telling her it was a good idea - he usually isn’t that nice to people (Session 9).

Although Mitch was not writing full justifications, he was demonstrating his mathematical thoughts verbally and through his drawings. 
Mitch’s inconsistencies were again illustrated in Session 10. He simply solved the problem and wrote the numerical answer without any justification or explanation. He responded to his partner's writing. However; due to their illegible penmanship I was unable to determine what they wrote. When I asked them for clarification, they could not remember their comments. During Session 12, Mitch participated by writing the correct answer but an incorrect math justification. He acknowledged his mistake when his partner pointed it out (Figure 6).

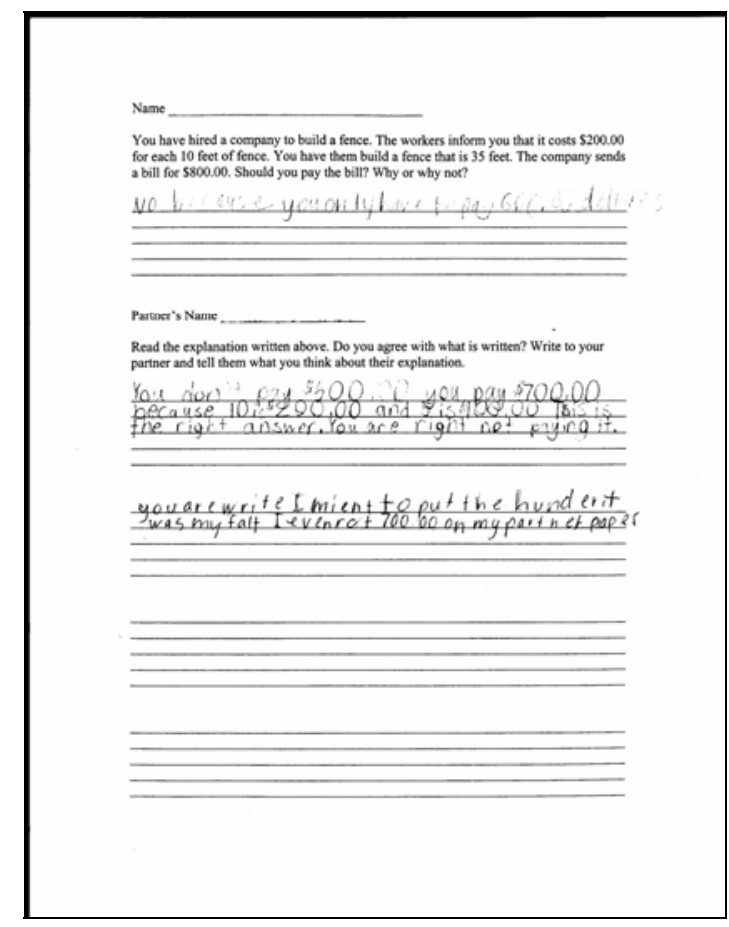

Figure 6 - Mitch Acknowledges His Mistake

During Session 16, I participated with Mitch in a small group discussion. He articulated his mathematical ideas and, when another student became confused by his explanation, he explained his reasoning again.

Teacher - Let's go down to the bottom one... look on the right hand side where it has the two...mumbling...we still don't know how much the cylinder 
weighs do we...let's go down to the bottom and look at the bottom one on the right hand side...we know the cubes weigh two and the sphere weighs four...

Mitch - I know something...

(Students are mumbling)

Teacher - Let Mitch talk.

Mitch - You know that them right there is two and we know these are four so you add them up and whatever you get you then um, that and that equals um four plus two is six and you gotta add them on and then after that you do that you have to figure out how much each of them weigh.

Teacher - Okay, so tell me what numbers you came up with - on this side how much did it weigh?

Mitch - On this side it weighs um, eighteen.

Teacher - Eighteen pounds ok, so if you know that is eighteen pounds, tell me what you know about this side.

Mitch - This weighs six and these each have to weigh something to get eighteen.

Teacher - What do each of those cylinders have to weigh?

Mitch - Six pounds

Teacher - Because...

Mitch - Because six plus six is twelve and four more is sixteen plus one more cube is eighteen. 
Teacher - Very good, so it evens out the bottom scale, did you see what he did?

(Students are mumbling)

Teacher - He knows that now the cylinder weighs...

Mitch - Six pounds.

Teacher - So go back to the top and how much does each of those sides weigh?

Mitch - Each one weighs (pause)

(Silence)

Several kids - Ten pounds

Teacher - They each weigh ten pounds.

Erica - Yeah, but you didn’t (mumbling)

Ricky - I don't' understand.

Teacher - Mitch could you explain it to Ricky...

Mitch - See you got three spheres and each one is four and that equals twelve alright? Then you get each of the cubes which we figured out were two and you add each of the cubes up and all them up and they get eighteen so...

Teacher - Okay, hold on do you understand that? Do you understand how he got eighteen?

Ricky -Yeah

Teacher - Okay 
Mitch - On this one you got the sphere and you got the cube that's six pounds then you know these equal gotta weigh six to get eighteen.

(Silence)

Mitch - Cause six plus six is twelve plus six more is eighteen.

During a discussion with me after Session 17, Mitch stated that he liked the small group discussion. When asked about prior activities and his unwillingness to participate, this opinionated student unveiled his insecurities. "I didn't want to be wrong. I didn't know what to ask."

This process helped me understand Mitch’s actions. His actions, which were viewed as annoying and rude, seemed to be the detour he took to get around a difficult problem. While his insecurities about his math ability beyond computation created a block, his desire to question everything could turn out to be an asset. “Help Me!” : Julie

If asked to describe Julie, I would use the word dramatic. If there is trouble brewing among the girls, chances are Julie is in the middle of it. Further compounding school issues, she was a very needy student in mathematics. She would compute to solve problems but could not give reasonable explanations for her procedural choice. She always had a question and never seemed to understand concepts. She was quick to say " $I$ don't understand" and often gave up easily. She frequently hesitated when responding to my questions, typically answering in a questioning tone. Through this experience with Julie, I came to realize that she actually had some very good insight into mathematics. 
Contrary to my initial beliefs her difficulty was in making connections between mathematical concepts and in finding words to articulate her thoughts.

Although "Help me!" are the words spoken by Julie whenever engaged in a new task, I came to learn they were rooted in her insecurities. Julie needed the opportunity to think aloud and manipulate math ideas. She struggled with an internal conflict. She needed to allow herself time to think things through. However, she would become frustrated and give up before allowing herself enough think time. It was faster to just compute. As I watched Julie examine the first activity, I knew immediately what her response would be...disbelief. She waved her hand, stared at me and made huffing noises. When I looked her way she mouthed, “Help me!” I struggled to stay in my seat. I desperately wanted to rescue her - after all she struggled and I didn’t want to frustrate her. I smiled at her and nodded my head. However, that did not appease her one bit - in fact I would say she became angry. Her hand went down and it now held her head. She tapped her pencil and continued with her noises. When I could resist no longer I would look at her and catch her squinting her eyes at me. I do believe if she could have thrown fire from those eyes I would have been burnt. When I walked around the room and passed her desk, she would grab at me and I could not help but laugh to myself. The paper from the first activity was full of erase marks, and her response to all her partner's questions and comments was “I don't know.” She never completely finished the first activity.

The fourth grade students were out of class during Session 2 leaving me with only the fifth grade. A pep talk combined with a much smaller group (10 students compared to 
25 students) created a different atmosphere from Session 1. During this experience, Julie attempted to engage in a meaningful written dialogue with her partner as she explained her reasoning (Figure 7).

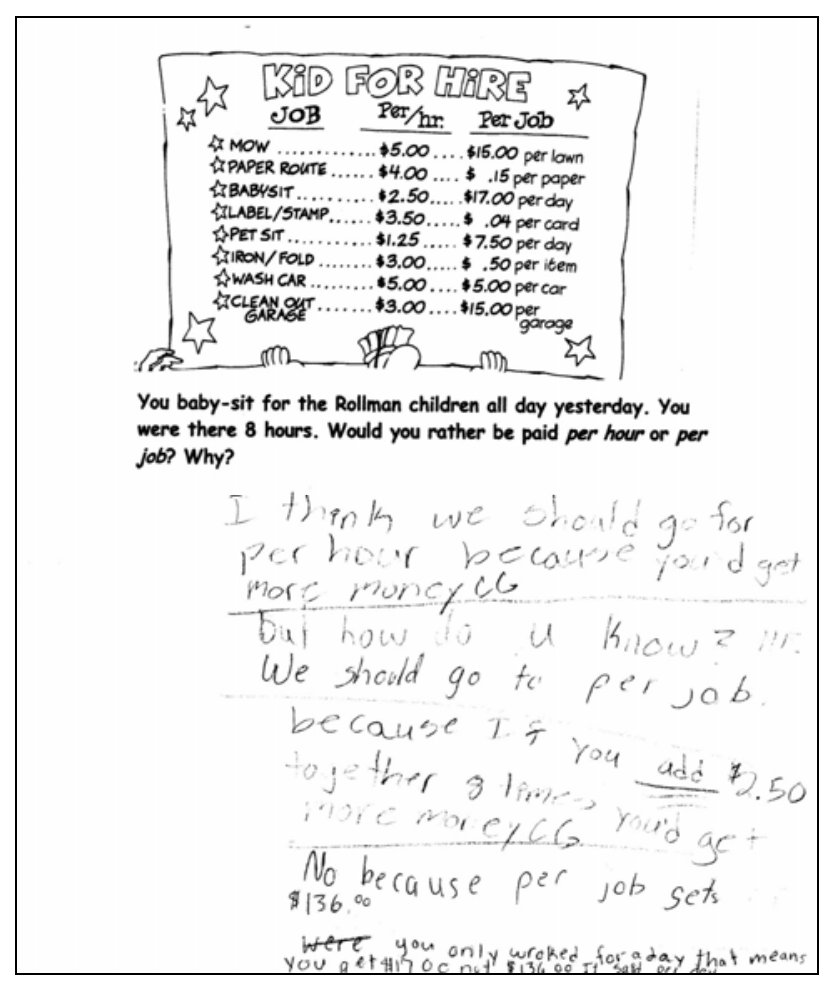

Figure 7 - Julie’s Explanation

During the class discussion in Session 2, Julie verbally explained her thinking: I picked per hour because if you add two dollars and fifty cents and two dollars fifty cents you get like four something. If you add four and four that means you get you might get eight something, you might get more than eight. Then like eight plus eight is already sixteen and is it's more than eight so you get more than seventeen cause it’s only one down from seventeen dollars so you're going to end up getting more than seventeen. 
When Rachel told her she did not follow, Julie again explained; "Like if you have two dollars and fifty cents and two dollars and fifty cents and two plus two is four you know when (pause) you're going to need to regroup with the fifty so it's more than four." The smile on her face after Rachel said she understood is priceless...but not lasting. Julie did think strategically and she could explain mathematical understandings, but it took time for her to articulate her thoughts in meaningful sentences. During Session 3, Julie participated by writing the mathematical procedure she considered for the problem. When her partner questioned her reasoning she gave an explanation that was unclear but convincing enough for her partner to agree with her (Figure 8).

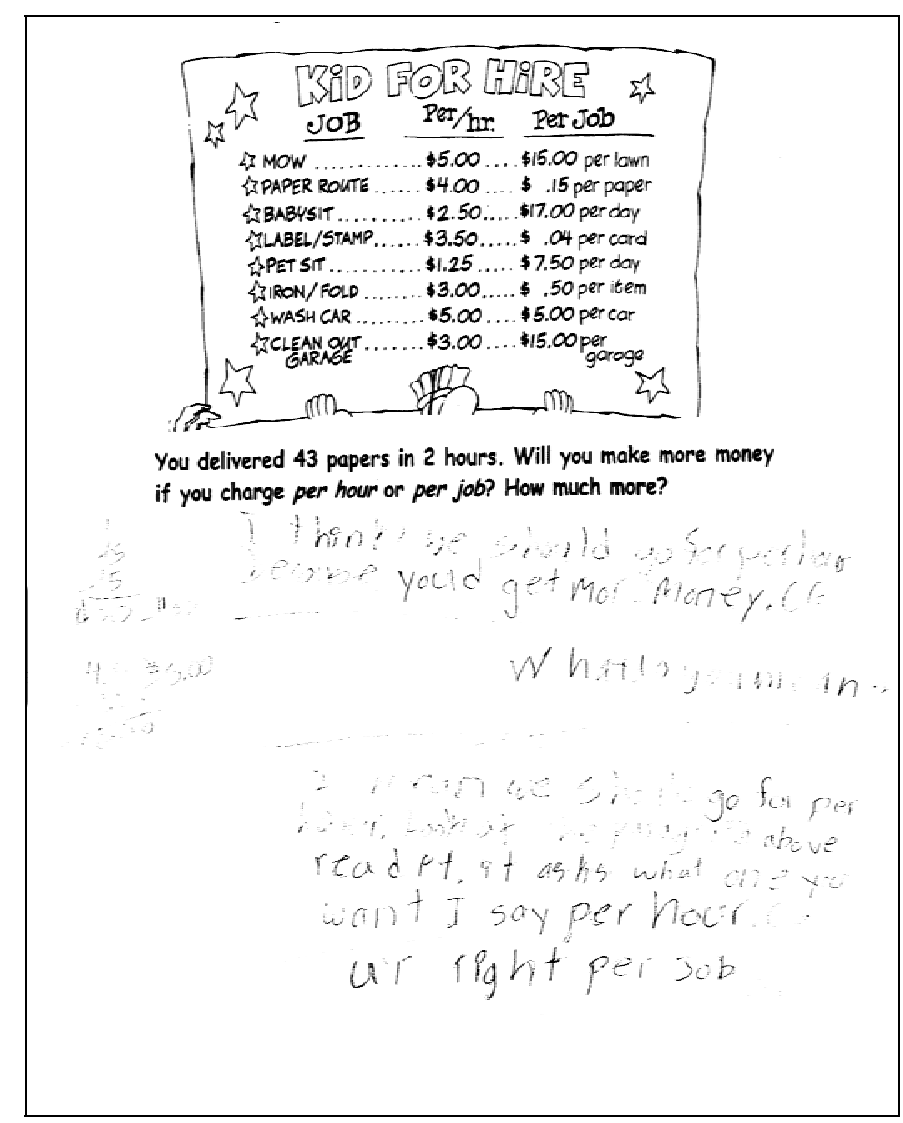

Figure 8 - Julie Convinces Her Partner 
For some reason, her writing in the next several sessions was limited. She often wrote silly comments to her partner, irrelevant to the problem. During group discussions she would simply read the written dialogue between her and her partner. However, at this time Julie began to take charge of the group discussions. She called on students to read their answers, even telling them what to read and when to read it.

A change occurred as time progressed and Julie began to respond to prompts without letting her frustration take over. In a discussion during Session 17, she realized her attempt to justify her answer mathematically was not going to work. Instead of allowing frustration to consume her, she tried another tactic. Julie justified her initial answer by stating: "I know that Kelsey got more but I'm sure that she is going to share some of her candy bar with her friend because that's what friends do and I bet she is a nice friend." When she was unable to use math to prove her answer she turned to character education, and nobody argued with her. Although this was not what I was looking for in terms of justifications, at least she was beginning to work through her frustration.

Perhaps Julie was a victim of enablers. All the assistance she received in mathematics, from both teachers and students, affirmed to her that she needed help. Julie was not confident with the accuracy of her mathematical understandings and demanded reassurance from others. As one of these enablers, I had to force myself to walk away and allow Julie to experience the trial and errors of mathematics. She had to be encouraged to think for herself and trust what she knew. Julie's self confidence in mathematics grew. She took control of the discussion groups and found her own paths to follow as she 
searched for answers. Julie needed time, she needed to allow herself time to really think through problems and make reasonable mathematical decisions. Looking Beyond the Obvious: Cooper

Cooper transferred to the school from a neighboring state in October, 2003. He had been living with his Dad, his Dad's girlfriend, and three of her children in a small trailer. As a victim of child abuse, he was court ordered to move in with his Mom, her boyfriend, and his son. Before Cooper enrolled in our school, his previous teacher called to prepare us for his arrival. He was diagnosed with both a behavior disorder and a learning disability, and he had previously been retained. The teacher from his former school described him as extremely disruptive and disrespectful. After an initial honeymoon period, he began to exhibit similar behaviors at our school. However, small moments of success kept us going. These small moments are illustrated through his experiences in this study.

It became clear very quickly that Cooper lacked basic mathematical knowledge. He struggled with both computation and application. Cooper had a strong need for a sense of security, and when it was threatened he would mentally shut down. He had a hard exterior shell and laughed in the face of anyone who made an effort to reach him. However, I found that patience and encouragement created cracks in his shell enabling him to learn. When I started expecting more from Cooper, and not allowing my knowledge of his situation to lower my expectations, changes started taking place. Not only did his classmates begin to expect more from him but he started expecting more from himself as well. 
Cooper was reluctant to participate in many class activities. However, I had developed a bond with Cooper, and he would comply with my requests putting forth effort on most activities. Cooper has been diagnosed with a language and writing disability. I assured him that spelling and grammar were not the focus of this writing, and stayed true to my word. I was pleasantly surprised that he participated in the written portion of the dialogue journaling activities. His writing generally included suggestions on how to solve the problems. Although not always meaningful, he made an effort in his responses to his partner's suggestions and comments. I noticed that Cooper's writing was bunched up, often writing up and down instead of left to right and he did not cross the center line. This was a previously undiagnosed problem. When presented with a paper where I had drawn lines for him he commented, “This is stupid!” He did however use the lines and in the next activity drew his own lines. Although Cooper did not make the same mathematical gains as other students in the class, the dialogue journal enabled me to diagnose a specific writing problem. This was possible because Cooper finally started to write.

While Cooper made attempts to write out his thoughts and questions, and while he would respond to his partner's writing, he often refused to let his partner see his paper. He would whisper to them, hiding his paper under his arm. These partners were students generally viewed as "good students” and liked by their classmates. Cooper cared what they thought.

An analysis of the small group discussions was very telling. During some discussions, Cooper was quiet and did not participate. Other times he would simply read 
what was written on his paper. Then there were times when he emerged as the leader. He introduced group members, stated the date, and "called” on group members to speak. During these times he controlled the tape recorder often ruining tapes by rewinding and taping over discussions. The actual group members did not affect his behavior. He was not always silly with some kids and quiet with others. Interestingly, Cooper's participation in class discussions was more productive than in the small group discussions. During one class discussion he stood and physically demonstrated what he was trying to say mathematically. Cooper was observed "sitting on the edge of his seat" (Session 9). He waited for an opportunity to add something to the discussion. After giving his thoughts, Cooper would look at me. If I did not immediately respond, he would repeat what he said often talking with his hands.

There were changes in Cooper's attitude and level of participation that could never be scored on a rubric. Cooper found his voice. He found that he could engage in a conversation about mathematics and offer assistance to the group through his ideas and explanations. The self-fulfilling prophecy that mapped out his original course began to change as he became an active, contributing member of the group.

These students' individual experiences illustrate how their view of mathematics began to change. What was once a numerical procedure, only requiring computation, was becoming an activity that required thought and strategic planning. As the students' view of mathematics began to change, so did their explanations and justifications. 


\section{Brief Constructed Responses}

Seven Brief Constructed Response (BCR) items were administered to students prior to the implementation of the study and five Brief Constructed Reponses (BCR) items were administered immediately following the seventeen sessions in which the dialogue journaling process took place. Each of these items was scored by a colleague familiar with the Maryland State Department of Education mathematics rubric. Based upon the rubric scoring, scores range from 0-2 (Appendix B). The average scores of both the Pre and Post BCR items are found in Table 1.

\begin{tabular}{|c|c|c|c|}
\hline \multicolumn{4}{|c|}{ Changes in Scores } \\
\hline & Pre & Post & Growth \\
\hline Mitch & .2 & 1.6 & 1.4 \\
\hline Austin & .6 & 1.5 & .9 \\
\hline Sarah & 1.6 & 1.6 & 0 \\
\hline Aaron & 1.0 & 1.4 & .4 \\
\hline Cory & .7 & .5 & -.2 \\
\hline Julie & 1.4 & 1.6 & .2 \\
\hline Jack & .7 & 1.2 & .5 \\
\hline Micky & .8 & 1.2 & .4 \\
\hline Carol & .8 & 1.4 & .6 \\
\hline Ricky & .4 & 1.2 & .8 \\
\hline Jimmy & 1.0 & 1.6 & .6 \\
\hline Erica & 1.6 & 1.2 & -.4 \\
\hline Cooper & 0 & .2 & .2 \\
\hline Ella & 1.2 & 1.6 & .4 \\
\hline Eddie & .6 & 1.6 & 1.0 \\
\hline Kristen & 1.0 & .8 & -.2 \\
\hline Alexandra & 1.4 & 1.6 & .2 \\
\hline Kevin & .6 & 1.0 & .4 \\
\hline Rachel & 1.8 & 1.6 & -.2 \\
\hline Dylan & & .6 & \\
\hline Joy & 1.0 & 1.4 & .4 \\
\hline Samantha & .4 & 1.0 & .6 \\
\hline Cindy & .6 & 1.6 & 1.0 \\
\hline
\end{tabular}

Table 1 - Brief Constructed Response Scores.

Note: Dylan was not included in the calculation of the statistics. 
The Post BCR scores improved for $70 \%$ of the students. Improvements on the scores ranged from 0.2 points (10\%) to 1.4 points (70\%) with the mean improvement being 0.7 points (35\%).

The increases in the BCR scores are a result of the explanations and justifications that students began to write. The responses to the portion of the Post BCR items requiring an explanation were more specific than on the initial BCR items. In addition, students began describing the strategy they used to solve the problem. "I solved the problem by doing a guess and check” (Erica, June 1, 2004); “I drew a picture of ...” (Rachel, June 1, 2004). Students also began giving more detailed descriptions of their calculations. " $I$ subtracted \$3.00 from .75 for the soda. Then I drew \$2.25 in quarters....” (Ella, June 1, 2004), and giving reasons for the explanations. "I think you should solve the problem by $x$-ing $10 \times 5$. Because it is 5 for a dollar and there is $10 \$ 1.00$ in ten dollars” (Alexandra, June 2, 2004). These examples illustrate the mathematical understandings of the students. They knew how to solve the problems and they knew why the procedures made sense.

The verbal and written discourse in the classroom contributed to the students' ability to express their mathematical thinking in writing. Students were becoming better at describing their thoughts, asking questions, and explaining their ideas. However, they needed guidance during verbal and written discussions. A comparison of verbal discussions and writing samples completed in the beginning, middle, and end of the study illustrate differences in the students' verbal and written dialogues. In the initial phase of the study, discussions were held as a question and answer activity (Session 3):

Cooper -I times forty-three times fifteen and that's my answer. 
Rachel - What did you get? Are you going per hour or per job?

Cooper - I’m going for job, per hour.

Rachel - And I'm going per hour, Kristen, what are you going for?

Kristen - Per hour.

Rachel - Mike, what are you going for?

Austin - Per hour

Rachel - Micky, what are you going for?

Micky - Per hour

Rachel - Jimmy, what are you going for?

Jimmy - Per hour

Rachel- Tell us how you got your answer. (Pause) How'd you get your answer? (Shuffling of papers)

Austin - He got his answer by fifteen...

Jimmy (interrupting Austin) - I multiplied forty-three times fifteen and I came up with eight fifty, eight fifty...' eight thirty five

Rachel - Eight dollars and thirty-five cents?

Jimmy - Yeah

Rachel - Okay and you're going for per hour? Ok, let’s listen to ourselves.

In this example, the discussion revolved around the final answer. Although at one point Rachel asked Jimmy how he got his answer, the focus was on computation. At no point did the students ask, "why?” or "how did you know to multiply?" This lack of discussion was also seen in the written dialogue between students (Figure 9). 


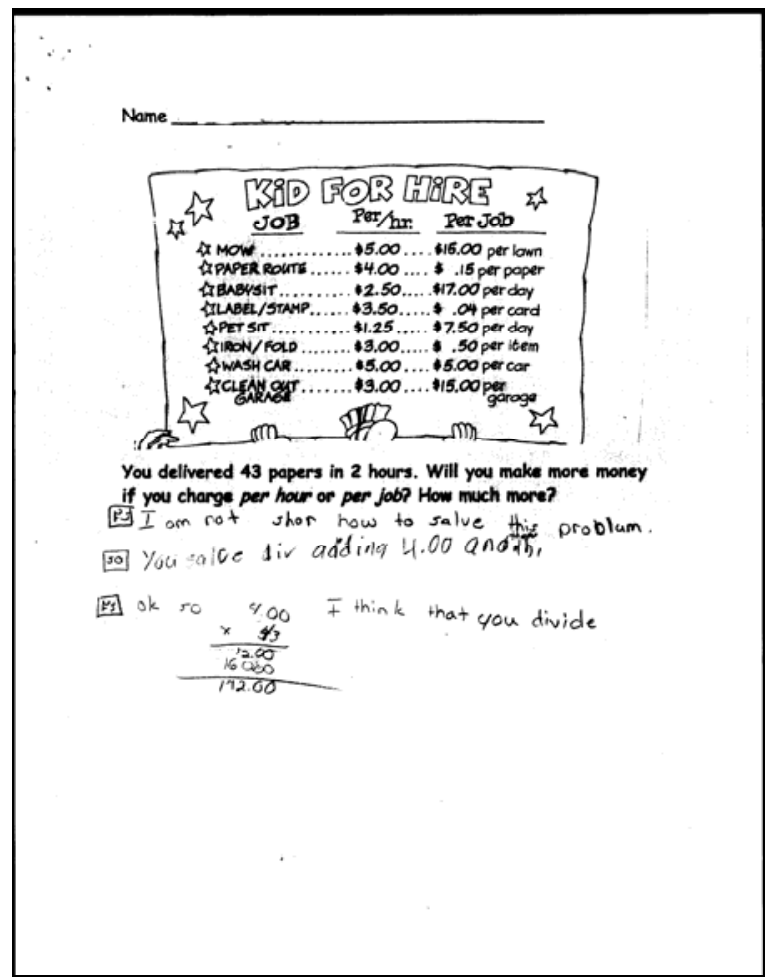

Figure 9 - Lack of Discussion

In this example, not only were the students referring to different mathematical procedures, but they were not aware that their ideas did not make sense. Their lack of mathematical understandings kept them from discussing a procedure that made sense.

After eight sessions, many discussions were including an explanation of how students solved the problem (Session 8):

Jimmy - It is May 5, Wednesday, 2004. In our group is Aaron, Ricky, Micky, Kristen, and Eddie. Aaron will go first.

Aaron - How to solve the problem, you could add all the jobs up and all the hours up.

Jimmy - Here’s Micky. 
Micky - You would use car wash, wash car and mow and stamps. You would mow for four hours and wash cars for four hours and do stamps for two hours.

Jimmy - And here is Jimmy. I would add fifteen and fifteen which is thirty and add (pause) car (pause) alright you work the car wash for four hours. Thirty and twenty is fifty so it's fifty dollars. And here is Kristen.

Kristen -You add fifteen and fifteen which is thirty and add twenty equals fifty dollars. You work four hours for the car wash and get twenty and add up to fifty because twenty and thirty equals fifty.

Jimmy - And here is a word from Ricky.

Ricky - First thing I put was I would clean two garages, and one lawn and one car for my three jobs. Then Micky put "not per job but per ours: and then I wrote "wash cars for one hour, now the lawn for three hours and clean garages for five hours.”

Jimmy - And here is a word from Eddie.

Eddie -You would add fifteen plus fifteen plus seventeen plus three which equals fifty and it would equal three jobs.

Although none of the students questioned one another and they allowed conflicting answers to be stated, the students were beginning to explain how they calculated their answers. In the written dialogue entries, occurring at the same time, some students began correcting one another and giving a reason for their ideas (Figure 10). 


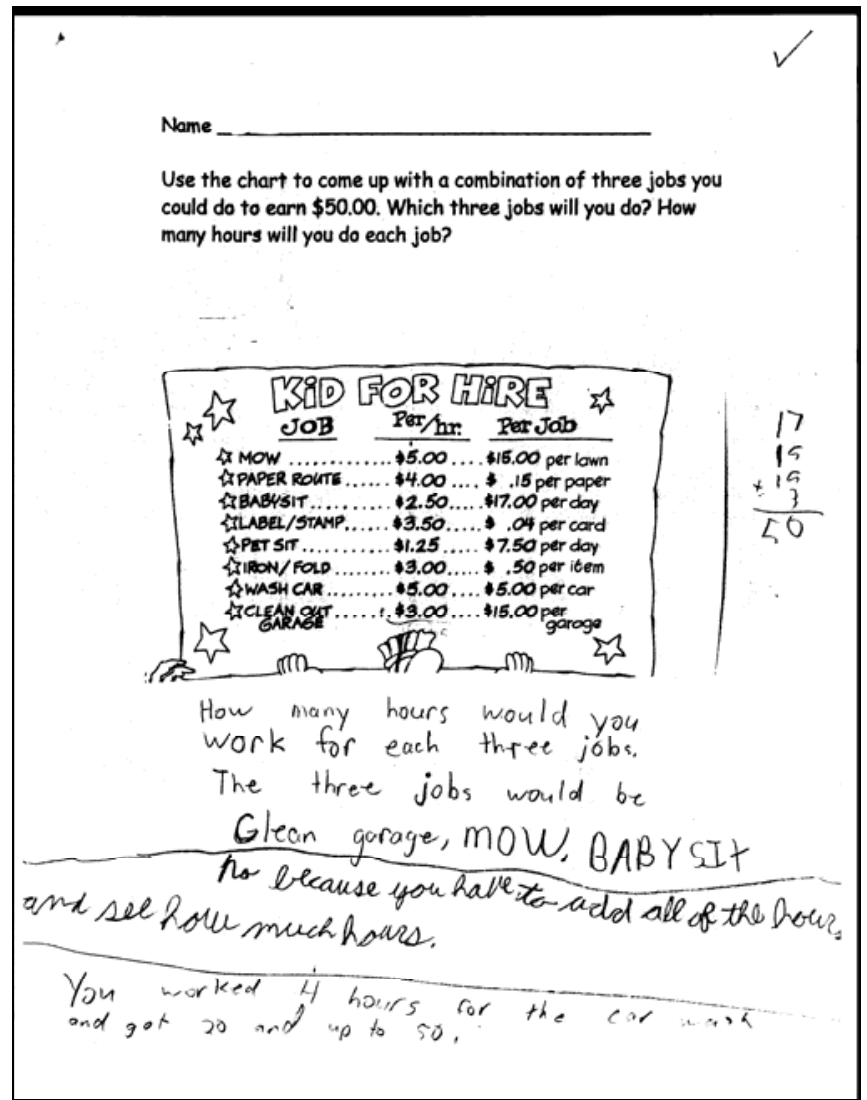

Figure 10 - Discussions Begin

Due to the lack of dialogue during the discussion portion of the process, I began to sit in on more of the discussions, encouraging students to stop and think logically. In this next example, taken from a class discussion during Session 17, the discussion is quite different. I was involved in the discussion and provided guidance and the opportunity for the students to think through their ideas.

Teacher - What can you tell me by looking at the scale?

Several kids - They are even

Teacher - Okay, there is equal weight on both sides...the questions are: what is the weight of the cylinder? What is the weight of the cube? How did you go about answering these questions? 
Aaron - I think the cube is two because half of four is two and I thought the cylinder is three.

Several kids - Oh

Teacher - So look at the picture -this and this are exactly the same - if we know this is four what are these?

Arguing between students

Teacher- See if that works, we know that this is four and this is, well, we don't know what that is, we are guessing the cubes are two, right? So go down here and figure it out, if you are saying the cubes are two what does this part of the scale weigh?

Micky- Um, wait...

Jimmy - Four, five, six, this would have to be um...Eighteen.

Teacher - If this is eighteen what does this side have to equal?

Aaron - Maybe you could like change them like the first one and the on the second one change it around...

(Mumbling)

Teacher - If this side is eighteen what does this side equal?

Several kids - Eighteen

Teacher - Okay, if this has to equal eighteen what are the cylinders?

(Mumbling then silence)

Teacher -Okay, you know the sphere is...what?

Several kids - Four 
Teacher - Okay, and the cube is what?

Several kids - Two

Teacher - Two, if it has to equal eighteen what are these two?

Several kids - Four, (mumbling then silence)

Teacher - What are you thinking Jimmy?

Jimmy - I don’t know, mumbling, um, four, two, six, oh!

Aaron- You can change them around...

Teacher - Hold on hold on let Jimmy finish... if it all has to equal eighteen and this is six what is this? Together what does this weigh?

(Silence)

Jimmy - This is um, six plus six, (mumbling). This one looks like it's about six pounds.

Teacher - Will that work? Figure it out...keep going...(mumbling)

Several kids - Six

Teacher - So your sphere equals what?

Jimmy - Four, the cube is two and the cylinder would be six.

(Mumbling)

Teacher - Once you looked at what you knew to be true you needed to figure the bottom ...sometimes you can’t do the problem in sequential order...kind of like reading you often have to read on then go back...

This example demonstrates how students, when prompted, were able to stop, think, and then give reasonable answers. The written dialogues, occurring toward the end of the 
study, included questions which encouraged students to discuss their ideas (Figure 11). In this example the partner disagrees and illustrates her reasoning. Her illustration demonstrates her mathematical understanding of division and how to calculate the cost of the fence.

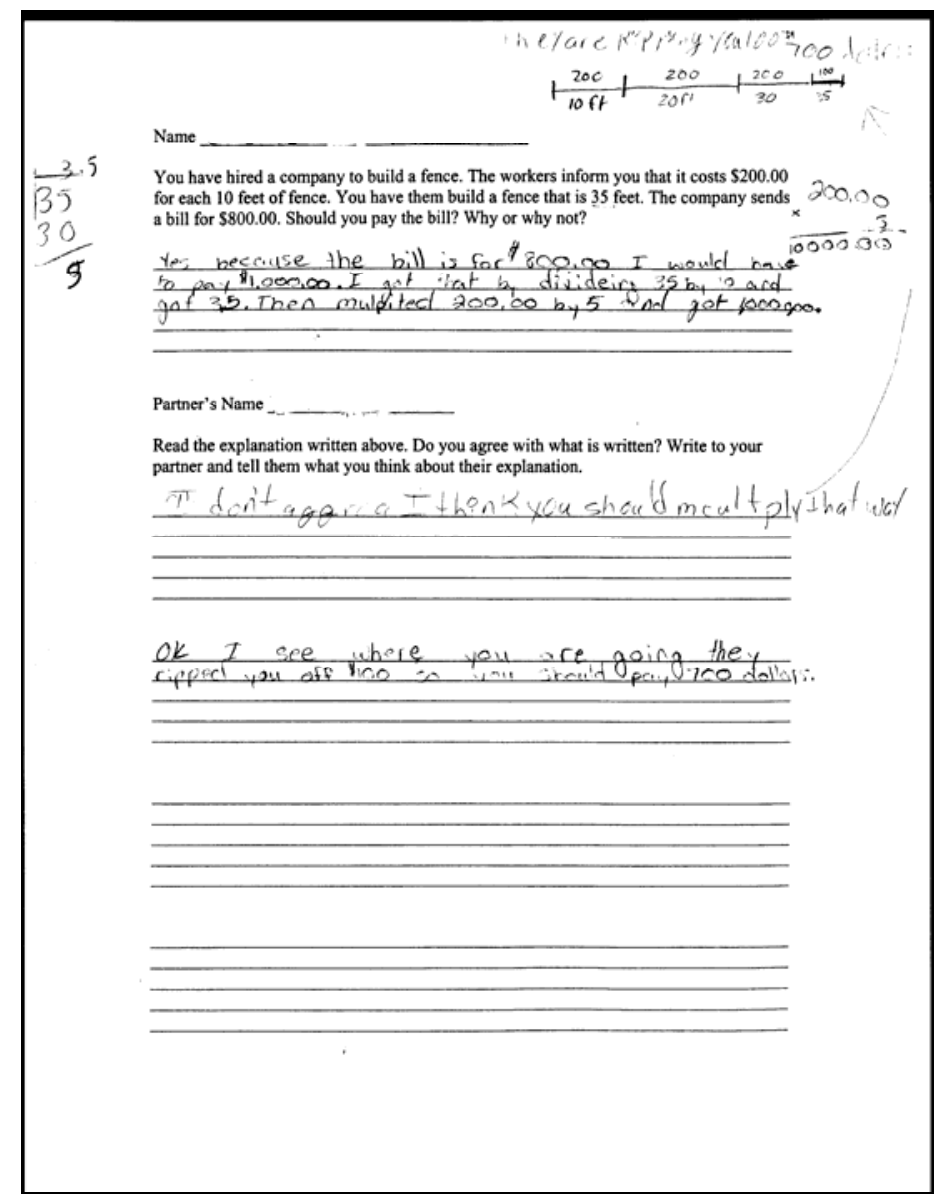

Figure 11 - Discussing Ideas

Mr. Smith (the scorer), indicated that he noticed a difference in the explanations students wrote on the Pre and Post BCR items. The Pre BCR items included the numerical answer to the problem. The explanations the students wrote were focused on the type of procedure they performed to get their numerical answer. For example, in 
September 2003, students were instructed to draw a figure that shows 3/8. The BCR portion of the prompt was "Use what you know about fractions to explain why your drawing is correct." Students explanations included; "You would color in 3 and draw 8. That's what I did" (Figure 12) and "My drawing is correct because I that the dedier is the bottom. The nemd is the top" (Figure 13). These examples demonstrate how students seemed to have some understanding of fractions, but they were not sure how those understandings fit together.

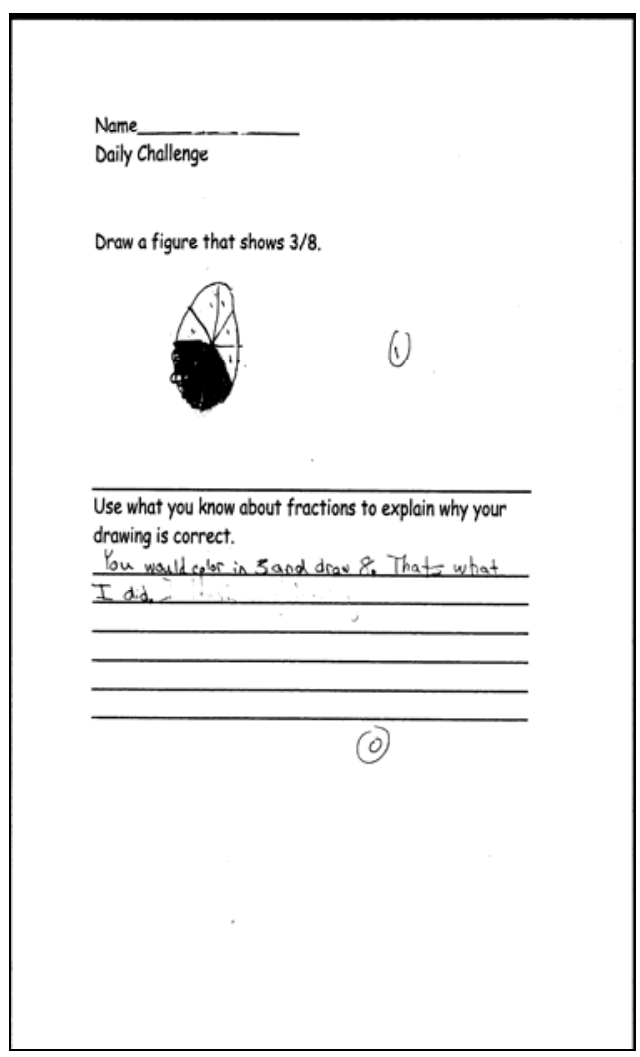

Figure 12 - Fraction Explanation 1

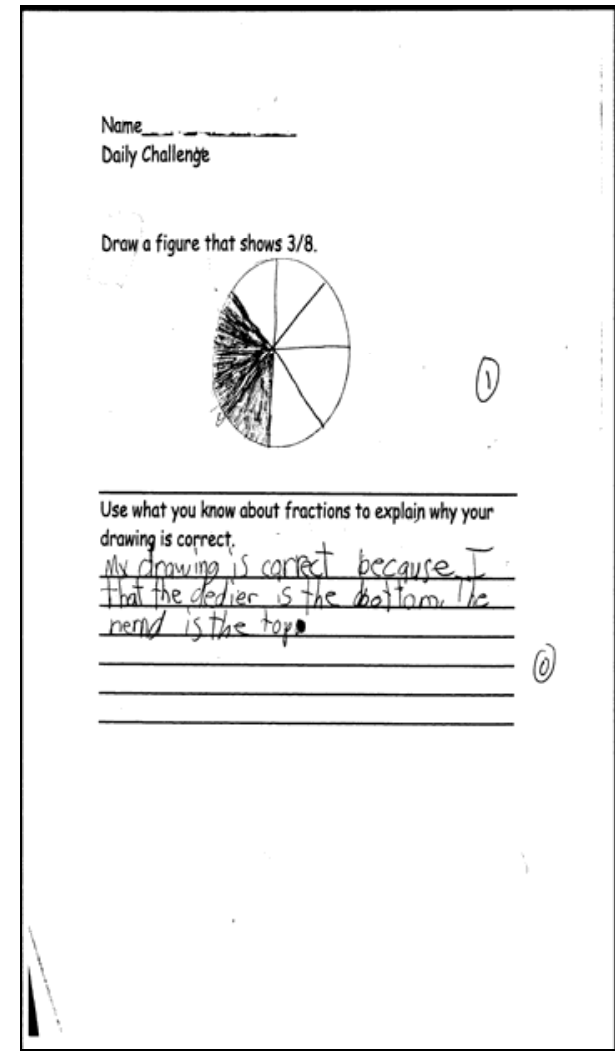

Figure 13 - Fraction Explanation 2

In the Post BCR items students included reasonable written justification for their answers (Figure 14) giving an increase in scores from 0 out of 2 to 2 out of 2 . The answer reflected the mathematical procedures the student calculated. The procedure chosen 
demonstrated her understanding of the mathematical concepts needed to solve the problem. In addition, Mr. Smith noted that the students began including the strategies they used to solve the problem. Figure 15 demonstrates how the student described the strategy she used in her explanation. The procedures used are sensible and illustrates her mathematical understandings. By responding to the prompt with a reasonable explanation students earned a higher score.

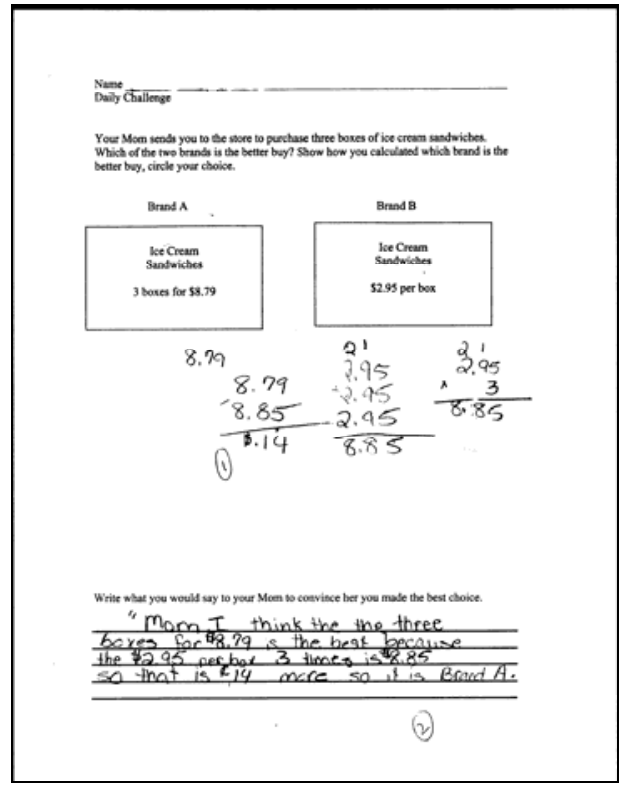

Figure 14 - Sensible Explanation 1

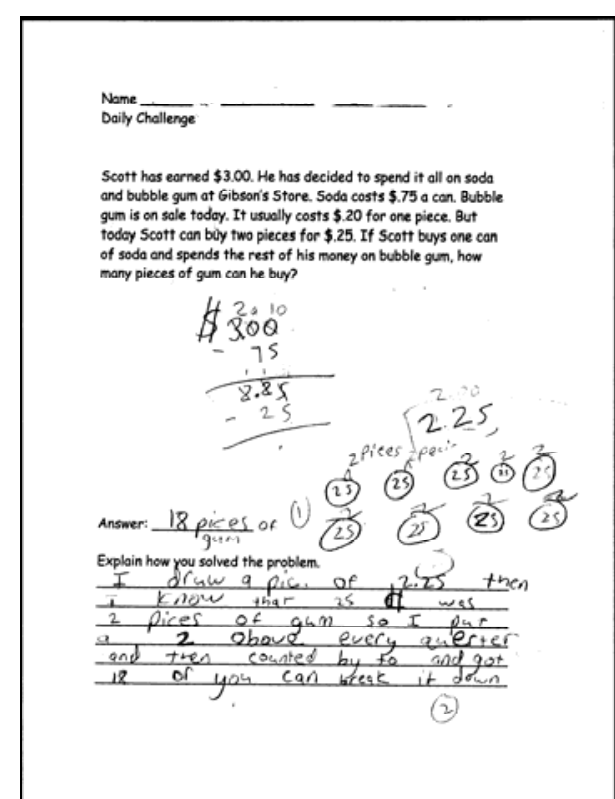

Figure 15 - Sensible Explanation 2

\section{Summary of Trip}

Each student entered the classroom with preconceived notions of what it means to do mathematics; mathematics was computation and nonverbal. The dialogue journaling process changed this view to mathematics as strategic and sensible. It also changed my perception of what it means to teach mathematics. Teaching mathematics was not telling but was listening. Through listening to oral discussions and reading written dialogues I 
was able to gain insight into the students' mathematical understandings. Consequently, the activities chosen and the questions asked assisted students in developing deeper conceptual understandings of mathematics as well as changing their views from mathematics as computation and nonverbal to math as strategic and sensible. 
Chapter 5

Reflecting on the Journey

\section{We shall not cease from exploration \\ And the end of all our exploring \\ Will be to arrive where we started And know the place for the first time.}

-T.S. Eliot (p. 145)

Prior to embarking on this journey, the path I was traveling with my class was not leading to mathematical conceptual understanding. We needed to take a detour off this old familiar path, and travel a new path. This new path needed to provide the opportunity for my students to express mathematical thoughts in verbal and written form. To travel this new path, we needed a vehicle that would encourage mathematical thinking and provide the opportunity for discourse. As their teacher, I needed a vehicle to help me understand their mathematical thinking. Through a review of the literature, I became familiar with a form of conversational writing known as dialogue journaling (Perry, 2001; McGrath, 1992; Gaustad \& Messenheimer-Young, 1991; Bode, 1989). This 
process was of interest because it served as a means for students to begin thinking about mathematical problems. In addition, the dialogue journaling process provided the opportunity for students to document their thoughts and questions, and participate in small group discussions. Dialogue journaling was the vehicle we used as we traveled down this new path, searching for mathematical understandings and the ability to explain those understandings. The questions which guided this study were:

1. What is the effect of dialogue journals and oral discussion on students' mathematical writing?

2. How are students' mathematical understandings reflected in their written and oral discussions?

The increase in the Post BCR scores suggests that the dialogue journals and oral discussions benefited the students' ability to write mathematically. The quality of the answers given by the students who had an increase in their scores was consistently better. Their responses contained mathematical justifications and, when requested, an explanation of the strategy used to solve the problem. The specific mathematical content making up the problem did not alter the quality of their response. The dialogue journaling process gave students the opportunity to unpack their thinking. They had to think about what they were being asked, how they could solve the problem, and their reasons for choosing that method. They practiced verbally defending their answers which assisted when writing justifications.

The written journal responses as well as the transcriptions of audio recordings provided insight into students’ mathematical understandings. It was often difficult for students to find the words to express what they were thinking, both in writing and orally. 
They were used to giving a numerical answer, not to expressing their mathematical thoughts. Misconceptions about mathematical procedures were evident as students struggled to write how they were going to solve a problem (Figure 16). Kristen did not know when to use mathematical procedures, and therefore did not truly understand the concepts. The fact that many students were unable or unwilling to discuss how they solved a problem demonstrated their lack of conceptual understanding or perhaps their lack of confidence in their understanding.

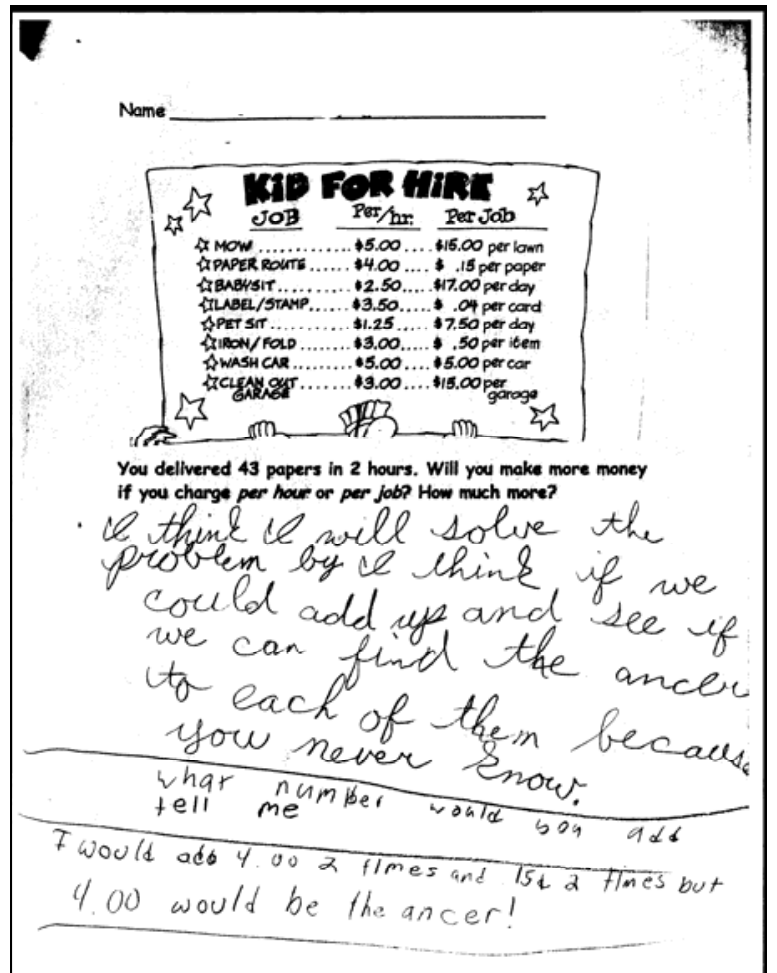

Figure 16 - Mathematical Misconceptions

\section{Encountering Roadblocks}

As we embarked on our journey we encountered several roadblocks. These roadblocks kept students from reaching a deeper understanding of mathematics. Initially, to many of my students, math was simply computing. When presented with a problem, 
they impulsively chose a procedure to calculate their answer. Unable to provide a logical explanation to support their choice, they could not reason or provide mathematical justifications. Students are taught to perform mathematics. They learn the rules for computation, and they learn to add, subtract, multiply, and divide. Traditionally, students are not encouraged to question the reasoning behind a procedure. When they do ask "why?" the response is often, "because that is the rule." They traditionally do not learn to connect concepts and are not typically required to justify their answer mathematically. To these students, the important part of math has always been the final answer. The thinking that led to the answer was not discussed and is reflected in their inability to write explanations on the BCR items.

This perception of mathematics is a direct result of instruction. Mathematics is what we, as teachers, make it. If we focus primarily on computation, then computation is what becomes important. While the ability to compute is certainly a necessary skill, the reason for computing should also be a priority. Students would often guess at the procedure they should follow, and they seemed to believe that if you guessed wrong, someone would tell you what procedure to perform. When a classmate suggested an alternative procedure for solving a problem, many of my students complied. This compliance occurred even if the alternate procedure was not followed with a logical mathematical reason. They were content to follow someone they perceived as having more authority (Amit \& Fried, 2002). The students rarely questioned their classmates' suggestions. These students assumed that if a classmate suggested a different procedure, that classmate must know what he was talking about. 
To many students, math was a silent activity. Because they believed that all you needed was a numerical answer, discussions were held in a round-robin fashion. Typically, students took their turn reading exactly what was written on their paper. Students did not question, ask for clarification, or disagree with their classmates. I wondered if the students' did not understand the concepts well enough to discuss them. Could it have been that connections between concepts were not being made? Was there no appropriate schema to hook the concepts too? Were they having difficulty discussing mathematics because they were unfamiliar with how to use language in mathematics? Was the difficulty the result of inexperience? As I reviewed the data and reflected on the experience, I concluded that the stilted discussions were a result of both lack of conceptual understanding and lack of appropriate mathematical language. Students did not truly understand many of the concepts and they were unfamiliar with using language in mathematics.

Benefits of the Process

Watching students work through the process benefited me, their teacher. I was able to get to know the students mathematically and plan for appropriate instructional assistance. I watched as they struggled with a problem and discovered their own best way of solving it. I found that students were not thinking through the problems. They had no plan for solving the problem and jumped directly into computing. As I began asking the question, "How do you think the problem should be solved?” students began developing a plan for solving the problem. Math was becoming strategic. While this question required students to think about the procedure they would utilize, it was not enough. Students responded to their partner’s response by answering the question, “Will the 
strategy described work? Why or why not?" This question gave students permission to disagree with their partners. They were able to state their opinions and give reasons. Many of the students were unable to constructively participate in a mathematical verbal discussion. Teacher participation in the discussions was needed to model questioning, to think aloud, and to encourage students to provide reasons for their answers. For many of my students, math was becoming sensible.

\section{Study Limitations}

There are a number of limitations which arise from the results of this study. With only 23 students participating, it is difficult to make generalizations. In addition, all 23 students were in the same classroom under the direction of the researcher, who served as their teacher. Replication in several classrooms involving more students with different teachers would add validity to these results. This study occurred over a period of six weeks and involved 17 sessions. This time limitation may have restricted the mathematical growth in students. Future research should engage students in the dialogue journaling process for longer periods of time. Another limitation is that there was only one scorer for the Brief Constructed Response items. Individual biases and expectations may have impacted the scores on both the Pre and Post Brief Constructed Response items. Previous mathematics instruction may have affected the results. Research examining the instructional style of mathematics teachers and the effect the instruction has on students' ability to discuss and write in mathematics would benefit the field.

\section{Instructional Considerations}

With the pressures of high stakes testing and the call for changes in mathematics instruction, it has become necessary for all of us to examine what and how we are 
teaching. For students to leave school with clear mathematical understandings, we need to be sure a strong foundation has been laid and that students are active in their mathematical learning. The difficulty these students had discussing mathematics reflected a lack of understanding of the concepts and limited experience with defending their ideas. It is difficult to ask a 10 year old to discuss and write about her thinking when she has not been given ample opportunities to practice.

Mathematical discussions should be held daily in all mathematics classrooms. Students' opinions should be verbalized and mathematically defended. This requires that teachers create an environment that is safe and supports risk taking. Teachers need to allow students time to think, share, reflect, and refine their answers. The format for discussions should include paired discussions, small group discussions, and whole class discussions. It is difficult for students to write what they can not verbally put into words. Therefore, it is important to begin by building a foundation utilizing oral language as a means to communicate mathematically, followed by putting thoughts in writing. This foundation needs to be constructed in the early years of mathematics instruction. Dialogue journaling supports this process. It provides a means for students to acknowledge their understandings, or lack of understandings, and ask questions.

To facilitate the process, teachers should begin asking students "why” more often and early in students' school career. Students need opportunities to wrestle with concepts and discuss their thinking. They should have experiences writing out their ideas and using mathematics vocabulary in both written and oral dialogues. Future studies are needed that focus on engaging young students in oral discussions and on appropriate questioning 
techniques for various age groups and cognitive abilities. Activities that invite and engage young students in building a mathematical foundation should be explored. Implications for Professional Development of Teachers

Before expecting students to view mathematics differently, we need to examine our knowledge of mathematics and our pedagogy. When asking teachers to change their instruction, we are often asking them to "give up” what is comfortable. Consequently, when a new instructional strategy does not quickly produce the expected results, teachers frequently revert back to the methods of instruction that are most comfortable to them. Therefore, many professional development programs fall short of creating a lasting change in the way teachers approach the teaching of mathematics.

Professional development activities need to consist of the same types of activities we are asking students to perform as well as provide time for reflection. Consideration needs to be given to the facilitator's background and the structure of the sessions. The facilitator should have a sound understanding of mathematics as well as experience with teaching students in the style being proposed. When discussing mathematical concepts, connections should be made as to hoe the concepts being taught in the elementary school lead to higher level mathematics as well as the importance of sequencing the activities to this end. With this destination in mind, teachers can connect and understand how their instruction in first or second grade builds the mathematical foundation necessary for higher level mathematics.

In addition to content knowledge, the facilitator should have experience teaching students utilizing the techniques being proposed. Real life vignettes of students’ mathematical activity provide participants with connections to their own experiences. 
Coupled with student examples, teacher participants should be given the opportunity to experience parallel activities. These activities should include asking the same type of questions we are asking students. Participants should be expected to explain their thinking, justify their answers, and connect their knowledge.

Since many elementary teachers are comfortable with their reading instruction, connections between mathematics instruction and reading instruction is vital. The similarity between what is being asked for in the mathematics classroom and current reading practices need to be explored. In reading we ask students to discuss and write about what they have read, we ask students to access prior knowledge and make connections, and we ask them to justify and support their answers. As seen in this study, these same techniques positively impact students’ approach to mathematics.

Professional development opportunities are needed to support teachers as they work toward changing students’ perception of mathematics and strengthening conceptual understandings. These opportunities should focus on the understanding and development of sequential activities that build upon foundations previously laid. Teachers need to experience the activities that cause them to make connections and require them to justify their thinking mathematically. It is through these types of activities that teachers will strengthen their own mathematical understandings and become comfortable with this type of instruction.

\section{Personal Reflection}

Through this experience, my personal opinions regarding mathematics and teaching have been altered. I watched my students struggle with concepts and ideas I previously assumed they understood. I now realize that I was doing most of the thinking 
for my students. I provided them with such structured activities and support that I took away any opportunity for them to wrestle with the material and understand the concepts. I have had to admit that I am not helping when I provide so much assistance that my students do not need to think. I realize that while I need to provide structure I also need flexibility in the activities to actively engage my students. They need to be doing more of the talking. I need to be quiet and listen. 


\section{Bibliography}

Abel, J. P., \& Abel, F. J. (1988). Writing in the mathematics classroom. Clearing House, 62(4), 155-158.

Adams, T. L. (2003). Reading mathematics: More than words can say. The Reading Teacher, 56(8), 786-795.

Amit, M., \& Fried, M. N. (2002). Authority in mathematics classroom and its influence on students' ability to reflect. Paper presented at the Annual Meeting of the International Group for the Psychology of Mathematics Education, Norwich, England.

Artzt, A. F. (1994). Integrating writing and cooperative learning in the mathematics class. Mathematics Teacher, 87(2), 80-85.

Baker, S., Gersten, R., \& Lee, D. S. (2002). A synthesis of empirical research on teaching mathematics to low-achieving students. The Elementary School Journal, 103(1), 51-73.

Ball, D. L. (1993). With an eye on the mathematical horizon: Dilemmas of teaching elementary school mathematics. The Elementary School Journal, 93(7), 373-397.

Battista, M. T. (1999). Fifth graders’ enumeration in cubes in 3D arrays: Conceptual progress in an inquiry-based classroom. Journal for Research in Mathematics Education, 30, 417-448.

Baxter, J. A., Woodward, J., \& Olson, D. (2001). Effects of reform-based mathematics instruction on low achievers in five third-grade classrooms. The Elementary School Journal, 101(5), 529-547. 
Baxter, J., Woodward, J., Voorhies, J. \& Wong, J. (2002). We talk about it, but do they get it? Learning Disabilities Research and Practice, 17(3), 173-185.

Bernero, J. (2000). Motivating students in math using cooperative learning. Unpublished master’s thesis, Saint Xavier University, Chicago, Illinois.

Billmeyer, R., \& Barton, M. L. (1998). Teaching reading in the content areas: If not me, then who? ( $2^{\text {nd }}$ ed.). Colorado: McRel.

Blessman, J. \& Myszczak, B. (2001). Mathematics vocabulary and its effect on student comprehension. Unpublished master’s thesis, St. Xavier University, Chicago, Illinois.

Blum, H. T, Lipsett, L. R., \& Yocom, D. J. (2002). Literature circles. Remedial \& Special Education, 23(2), 99-108.

Bode, B. A. (1989). Dialogue journal writing. Reading Teacher, 42(8), 568-571.

Borko, H., Eisenhart, M., Brown, C. A., Underhill, R. G., Jones, D., \& Agard, P. C. (1992). Learning to teach hard mathematics: Do novice teachers and their instructors give up too easily? Journal for Research in Mathematics Education, 23, 194-222.

Bratina, T. A., \& Lipkin, L. J. (2003). Watch your language! Recommendations to help students communicate mathematically. Reading Improvement, 40(1), 3-12.

Bromley, K., \& Modio, M. (1997). Using cooperative learning to improve reading and writing in language arts. Reading and Writing Quarterly, 13(1), 21-35.

Burns, M. (1995). Writing in math class? Absolutely! Instructor, 104(7), 40-46.

Burns, M. \& Silbey, R. (2000). So you have to teach math? Sound advice for K-6 teachers. California: Math Solutions Publications. 
Cai, J., \& Jakabcsin, M. S. (1996). Assessing students’ mathematical communication. School Science \& Mathematics, 96(5), 238-246.

Candl, L. (2004). Cooperative learning structure: Think-pair-share. http://home.att.net/ clnetwork/thinkps.htm

Carpenter, T. P., \& Lehrer, R. (1999). Teaching and learning mathematics with understanding. In E. Fennema \& T.A. Romberg (Eds.), Mathematics classrooms that promote understanding (p. 19-32). Mahwah, NJ: Erlbaum.

Cobb, P. (1999). Individual and collective mathematical development: The case of statistical data analysis. Mathematical Thinking \& Learning, 1(1), 5-43.

Cobb, P., Stephan, M., McClain, K., \& Gravemeijer, K. (2001). Participating in classroom mathematical practices. Journal of the Learning Sciences, 10(1/2), 113-164.

Cobb, P., Wood, T., \& Yackel, E. (1993). Discourse, mathematical thinking, and classroom practice. In E. Forman, N. Minisk, \& C. Stone (Eds). Contexts for learning: Sociocultural dynamics in children's development (91-119). New York: Oxford University Press.

Cobb, P., Wood, T., Yackel, E., \& McNeal, B. (1992). Characteristics of classroom mathematics traditions: An interactional analysis. American Education Research Journal, 29, 573-604.

Cooper, J. D. (2000). Literacy: Helping children construct meaning (4 ${ }^{\text {th }}$ ed.). Boston: Houghton Mifflin Company.

Cornell, C. (1999, Summer). I hate math! I couldn’t learn it, and I can’t teach it! Childhood Education, 75(4), 225-230. 
Creed, T. (1996). Think-pair-share-discuss. Cooperative Learning and College Teaching, 7(1). Retrieved September 26, 2004, from http://employees.csbsju.edu/TCREED/tpsd.html

Crespo, S. M. (2003). Using math pen-pals letters to promote mathematical communication. Teaching Children Mathematics, 10(1), 34-40.

Cuban, L. (1993). How teachers taught ( $2^{\text {nd }}$ ed.). New York: Teachers College Press.

DiPillo, M. L., Sovchik, R., \& Moss, B. (1997). Mathematics Teaching in the Middle School 2(5), 308-314.

Draper, R. J. (2002). School mathematics reform, constructivism, and literacy: A case for literacy instruction in the reform-oriented math classroom. Journal of Adolescent \& Adult Literacy, 45(6), 520-530.

Dusterhoff, M. (1995). Why write in mathematics? Teaching PreK-8, 25(4), 48-49.

Dynak, J. (1997). Structuring literacy course tasks to foster deliberate use of strategy instruction by preservice math teachers. Journal of Adolescent \& Adult Literacy, 40, 280-285.

Ediger, M. (2000). Speaking activities and reading. Reading Improvement, 37(3), 137146.

Eliot, T. S. (1971). The collective poems and place of T.S. Eliot: 1909-1950. New York: Harcourt, Brace, and World.

Englert, C. S. (1992). Writing instruction from a sociocultural perspective: The holistic, dialogic, and social enterprise of writing. Journal of Learning Disabilities, 25(3), 153-172. 
Fennema, E., Carpenter, T. P., Franke, M.L., Levi, L., Jacobs, V.R. \& Empson, S.B. (1996). A longitudinal study of learning to use children's thinking in mathematics instruction. Journal for Research in Mathematics Education, 27(4), 403-435.

Forman, E. A. \& Cazden, C. B. (1994). Exploring Vygotskian perspectives in education: The cognitive value of peer interaction. In R. B. Ruddell, M. R. Ruddell, \& H. Singer (Eds), Theoretical models and processes of reading (pp. 155 - 178). Newark, DE: International Reading Association, Inc.

Fortescue, C. M. (1994). Using oral and written language to increase understandings of math concepts. Language Arts, 71(8), 576-580.

Fountas, I. C., \& Pinnell, G. S. (1996). Guided reading: Good first teaching for all children. Portsmouth, NH: Heineman.

Fraivillig, J., Murphy, L., \& Fuson, K. (1999). Advancing children’s mathematical thinking in Everyday Mathematics classrooms. Journal for Research in Mathematics Education, 30, 148-170.

Franke, M. L., Carpenter, T., Fennema, E., Ansell, E., \& Behrend, J. (1998). Understanding teachers' self-sustaining, generative change in the context of professional development. Teaching and Teacher Education, 14, 67-80.

Fuchs, L. S., Fuchs, D., Hamlett, C. L., \& Appleton, A. C. (2002). Explicitly teaching for transfer: Effects on the mathematical problem-solving performance of students with mathematics disabilities. Learning Disabilities \& Practices, 17(2), 90-106. 
Fuchs, L. S., Fuchs, D., Hamlett, C. L., \& Karns, K. (1998). High-achieving students' interactions and performances on complex mathematical tasks as a function of homogeneous and heterogeneous pairings. American Educational Research Journal, 35(2), 227-267.

Fulwiler, T. (1987). Teaching with writing. Upper Monclair, New Jersey: Boynton/Cook Publishers.

Gaustad, M. G., \& Messenheimer-Young, T. (1991). Dialogue journals for students with learning disabilities. Teaching Exceptional Children, 23(3), 28-32.

Goldman, S. R. \& Hasselbring, T. S. (1997). Achieving meaningful mathematics literacy for students with learning disabilities. Journal of Learning Disabilities, 30(2), 198-109.

Goldsby, D. S., \& Cozza, B. (2002). Writing samples to understand mathematical thinking. Mathematics Teaching in the Middle School, 7(9), 517-520.

Greenes, C. E., Findell, C. R., Gavin, M. K., \& Sheffield, L. J. (2000). Awesome math problems for creative thinking. Chicago, Illinois: Creative Publications, Inc.

Gregg, J. (1995). The tensions and contradictions of the school mathematics tradition. Journal for Research in Mathematics Education, 26, 442-466.

Huggins, B., \& Maiste, T. (1999). Communication in mathematics. Unpublished master's thesis. Saint Xavier University, Chicage, Illinois.

Jaramillo, J. A. (1996). Vygotsky’s sociocultural theory and contributions to the development of constructivist curricula. Education, 117(1), 133-140. 
Jitendra, A. K., \& Hoff, K. (1996). The effects of schema-based instruction on the mathematical word-problem-solving performance of students with learning disabilities. Journal of Learning Disabilities. 29(4), 422-431.

Jones, R. (2002). Strategies for reading comprehension: Think-pair-share. http://curry.edschool.virginia.edu/go/readquest/strat/tps.html

Jurdak, M., \& Abu Zein, R. (1998). The effect of journal writing on achievement in and attitudes toward mathematics. School Science \& Mathematics, 98(8), 412-419.

Kagan, S. (1990). The structural approach to cooperative learning. Educational Leadership, 47(4), 12-15.

Kazemi, E. (1998). Discourse that promotes conceptual understandings. Teaching Children Mathematics, 4(7), 410-414.

Kazemi, E., \& Stipek, D. (2001). Promoting conceptual thinking in four upperelementary mathematics classrooms. The Elementary School Journal, 102(1), 5980.

Keene, E. O., \& Zimmerman, S. (1997). Mosaic of thought: Teaching reading comprehension in a reader's workshop. Portsmouth, NH: Heinemann.

Knuth R. A. \& Jones, B. F. (1991). What does research say about mathematics? North Central Regional Educational Laboratories (On-line), 7/31/01. Available http://www.ncrel.org/sdrs/areas/tw-esys/2math.html

Maloch, B. (2002). Scaffolding student talk: One teacher's role in literature discussion groups. Reading Research Quarterly, 37(1), 94-112.

Manzo, A. V., Manzo, U. C., \& Estes, T. H. (2001). Content area literacy: Interactive teaching for active learning ( $3^{\text {rd }}$ ed.). New York: John Wiley \& Sons. 
Maryland State Department of Education. (2004). www.msde.org.

McGrath, M. (1992). Writing before speaking: How the dialogue journal stimulates conversation. Unpublished master's thesis, Biola University.

McGuire, M. \& Harshman, K. (2002). The role of discourse in mathematical inquiry. (ERIC Document Reproduction Service No. ED470662).

McIntosh, M. E. (1991). No time for writing in your class? Mathematics Teacher, 84(6), 423-433.

McIntosh, M. E., \& Draper, R. J. (2001). Using learning logs in mathematics: Writing to learn. Mathematics Teacher, 94(7), 554-557.

Mercer, C. D., \& Lane, H. B. (1996). Empowering teachers and students with instructional choices in inclusive settings. Remedial \& Special Education, 17(4), 226-237.

Millard, E. S., Oaks, T. L., \& Sanders, T.M. (2002). Improving student achievement through inclusion of problem solving in the math curriculum. Unpublished thesis, Saint Xavier University, Chicago, Illinois.

Monroe, E. E., \& Orme, M. P. (2002). Developing mathematical vocabulary. Preventing School Failure, 46(3).

Motivation Stations, 2000. The real world of math ( $2^{\text {nd }}$ ed). www.motivationstations.com.

National Council of Teachers of Mathematics. (1989). Curriculum and evaluation standards for school mathematics. Reston, VA: Author.

National Council of Teachers of Mathematics. (1991). Professional standards for teaching mathematics. Reston, VA: Author. 
National Council of Teachers of Mathematics. (1995). Assessment standards for school mathematics. Reston, VA: Author.

National Council of Teachers of Mathematics. (2000). Principles and standards for school mathematics. Reston, VA: Author.

National Staff Development Council. (2000). www.nsdc.org/words.html

Nattiv, A. (1994). Helping behaviors and math achievement gains of students using cooperative learning. The Elementary School Journal, 94(3), 285-297.

O’Brien, D. G., Stewart, R. A., \& Moje, E. B. (1995). Why content literacy is difficult to infuse into the secondary school: Complexities of curriculum, pedagogy, and school culture. Reading Research Quarterly, 30, 442-463.

Owens, R. L., \& Fuchs, L. S. (2002). Mathematical problem-solving strategy instruction for third grade students with learning disabilities. Remedial \& Special Education, 23(5), 268-279.

Patton, M. Q. (2002). Qualitative research \& evaluation methods ( $3^{\text {rd }}$ ed.). California: Sage Publishing.

Perry, J. (2001). Negotiating meaning, demonstrating understandings: Perceptions and intentions in fifth-graders' mathematical communications. Unpublished doctoral dissertation, University of Central Florida, Orlando, Florida.

Pimm, D. (1987). Speaking mathematically: Communication in mathematics classrooms. New York: Routledge.

Polaki, M. V. (2002). Using instruction to identify key features of Basotho elementary students' growth in probabilistic thinking. Mathematical Thinking and Learning, 4(4), 285-313. 
Powell, A. B. (1997). Capturing, examining, and responding to mathematical thinking through writing. Clearinghouse, 71(1), 21-24.

Pugalee, D. K. (1997). Connecting writing to the mathematics curriculum. Mathematics Teacher, 90(4), 308-310.

Pugalee, D. K. (2001). Writing, mathematics, and metacognition: Looking for connections through students' work in mathematical problem solving. School Science and Mathematics, 101(5), 263-246.

Putnam, R. T., Heaton, R. M., Prawat, R. S., \& Remilliard, J. (1992). Teaching mathematics for understanding: Discussing case studies of four fifth-grade teachers. Elementary School Journal, 93, 213-228.

Quinn, R. J., \& Wilson, M. M. (1997). Writing in the mathematics classroom: Teacher beliefs and practices. Clearinghouse, 71(1), 14-20.

Rasmussen, K. (Summer 1999). Break the chain. ASCD Curricular Update, 2-3.

Ruddell, M. R. (1997). Teaching content area reading and writing ( $2^{\text {nd }}$ ed.). Boston: Allyn \& Bacon.

Rudnitsky, A., Etheredge, S., Freeman, J. M., Gilbert, T. G. (1995). Learning to solve addition and subtraction problems through a structure-plus-writing approach. Journal for Research in Mathematics Education, 26(5), 467-486.

Schroeder, M.A. \& Burma-Washington, M. (1993). I can't believe it's math: Discovering classroom math in after-school activities. Hudson, NH: Delta Education

Sharp, J., \& Adams, B. (2002). Children's constructions of knowledge for fraction division after solving realistic problems. The Journal of Education Research, 95(6), 334-347. 
Silver, H. F., Strong, R. W., \& Perini, M. J. (2000). So each may learn. Virginia: Association for Supervision and Curriculum Development.

Smith, J. P. III (1996). Efficacy and teaching mathematics by telling: A challenge for reform. Journal for Research in Mathematics Education, 27, 387-402.

Steele, D. F. (2001). Using sociocultural theory to teach mathematics: A Vygotskian perspective. School Science and Mathematics, 101(8), 404-416.

Taberski, S. (2000). On solid ground. Portsmouth: Heinemann.

Thornton, C. A., \& Langrall, C. W. (1997). Mathematics instruction for elementary students with learning disabilities. Journal of Learning Disabilities, 30(2), 142150.

Tomlinson, C. A. (2001). How to differentiate instruction in mixed-ability classrooms. Virginia: Association for Supervision and Curriculum Development.

Vacca, R. T., \& Vacca, A. L. (1996). Content area reading (5 ${ }^{\text {th }}$ ed.). NY: Harper Collins/College.

Wall, M. E., \& Dattilo, J. (1995). Creating option-rich environments: Facilitating selfdetermination. The Journal of Special Education, 29, 276-294.

Wertsch, J. V. (Ed.). (1981). The concept of activity in Soviet psychology. Armonk, NY: Sharpe.

Whitin, D. J., Whitin, P. (2003). Talk counts: Discussing graphs with young children. Teaching Children Mathematics, 10(3), 142-149.

Whitin, P., \& Whitin, D. (2002). Promoting communication in the mathematics classroom. Teaching Children Mathematics, 9(4), 205-212. 
Wickett, M. S. (2000). Nurturing the voices of young mathematicians with dyads and group discussions. Teaching Children Mathematics, 6(6), 412-415.

Williams, S. R., \& Baxter, J. A. (1996). Dilemmas of discourse-oriented teaching in one middle school mathematics classroom. The Elementary School Journal, 97(1), 2138.

Winograd K., \& Higgins, K. (1994-5). Writing, reading, and talking mathematics: One interdisciplinary possibly. Reading Teacher, 48(4), 310-319.

Wood, K. D., \& Algozzine, B. (1997). Introduction: Cooperative learning across the curriculum. Reading \& Writing Quarterly, 13(1), 3-5.

Wood, T., Cobb, P., \& Yackel, E. (1991). Change in teaching mathematics: A case study. American Educational Research Journal, 28, 587-616.

Woodward, J. \& Baxter J. (1997). The effects of an innovative approach to mathematics on academically low achieving students in inclusive settings. Exceptional Children, 63(3), 373-388.

Woodward, J., Monroe, K., \& Baxter J. (2001). Enhancing student achievement on performance assessments in mathematics. Learning Disabilities Quarterly, 24, 33-46.

Woodward, J., \& Montague, M. (2002). Meeting the challenge of mathematics reform for students with learning disabilities. Journal of Special Education, 36(2), 89-102.

Ziglar, Z. (1997). Something to smile about: Encouragement and inspirations for life's ups and downs. Nashville Tennessee: Thomas Nelson, Inc. 


\section{Appendix A}

Brief Constructed Response Item

Jennifer needs to put up a fence around her backyard. Her backyard is shown below.

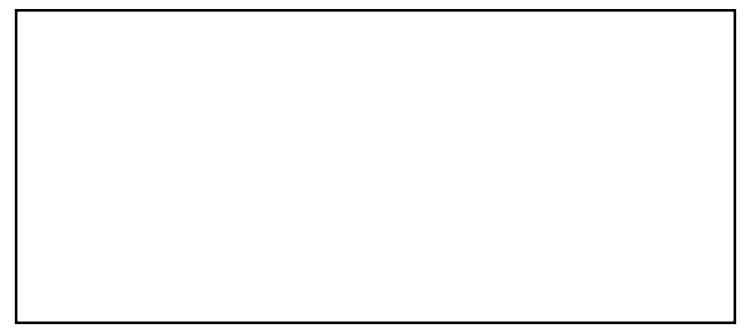

Step A

Classify the shape of Jennifer’s backyard.

\section{Step B}

Use what you know about quadrilaterals to explain how you classified the shape of Jennifer's backyard. Use words, numbers, and/or symbols in your explanation.

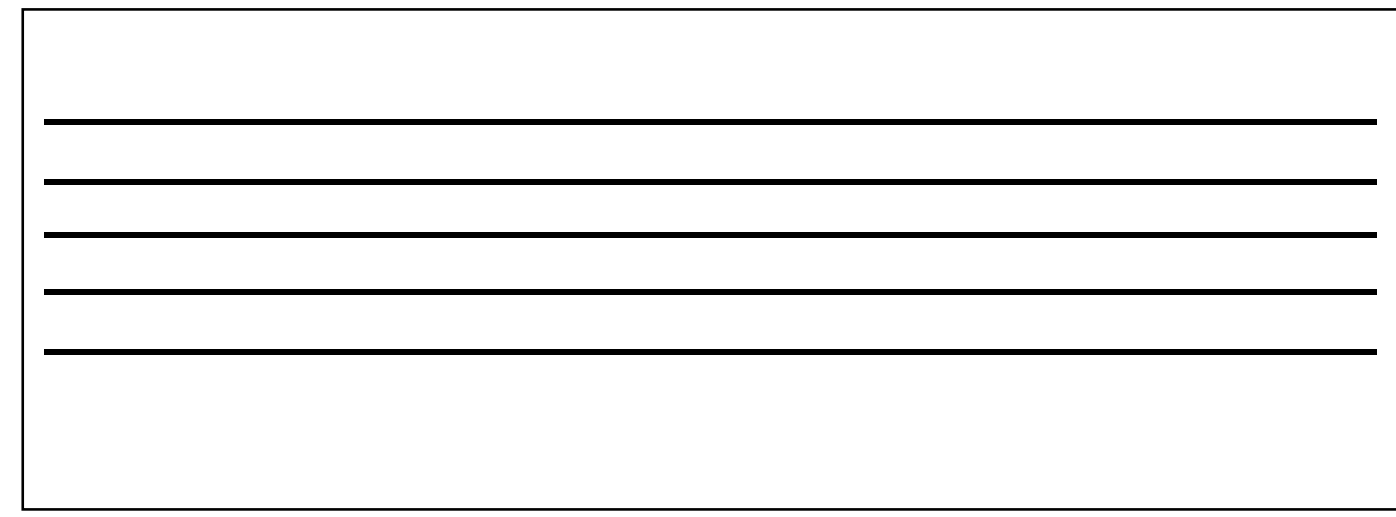




\section{Appendix B}

\section{Brief Constructed Response Rubric}

2 The response demonstrated a complete understanding and analysis of a problem.

*Application of a reasonable strategy in the context of the problem is indicated.

*Explanation of and/or justification for the mathematical process(es) used to solve a problem is clear, developed, and logical.

*Connections and/or extensions made within mathematics or outside mathematics are clear.

*Supportive information and/or numbers are provided as appropriate.

1 The response demonstrated a minimal understanding and analysis of a problem.

*Partial application of a reasonable strategy in the context of the problem is indicated.

*Explanation of and/or justification for the mathematical process(es) used to solve a problem is partially developed, logically flawed, or missing.

*Connections and/or extensions made within mathematics or outside mathematics are partial or overly general, or flawed.

*Supportive information and/or numbers may or may not be provided as appropriate.

0 The response is completely incorrect, irrelevant to the problem, or missing.

Notes:

Explanation refers to students' ability to communicate how they arrived at the solution for an item using the language of mathematics.

Justification refers to students' ability to support the reasoning used to solve the problem, or to demonstrate why the solution is correct using mathematical concepts and principles.

Students need to complete rubric criteria for explanation, justification, connections and/or extension as cued in a given problem.

An exact copy or paraphrase of the problem that provides no new relevant information will receive a score of “ 0 ”. 
Appendix C

Recording Sheet

Date:

Topic:

\begin{tabular}{|c|c|c|}
\hline Observations & Impressions & Analysis of Observations \\
\hline & & \\
\hline & & \\
\hline & & \\
\hline & & \\
\hline & & \\
\hline & & \\
\hline & & \\
\hline & & \\
\hline & & \\
\hline & & \\
\hline & & \\
\hline & & \\
\hline & & \\
\hline & & \\
\hline & & \\
\hline & & \\
\hline
\end{tabular}

Immediate Reflection of Lesson 
Fleshing-Out Notes

Date: 
Appendix D

Dialogue Journaling Activities 
Name

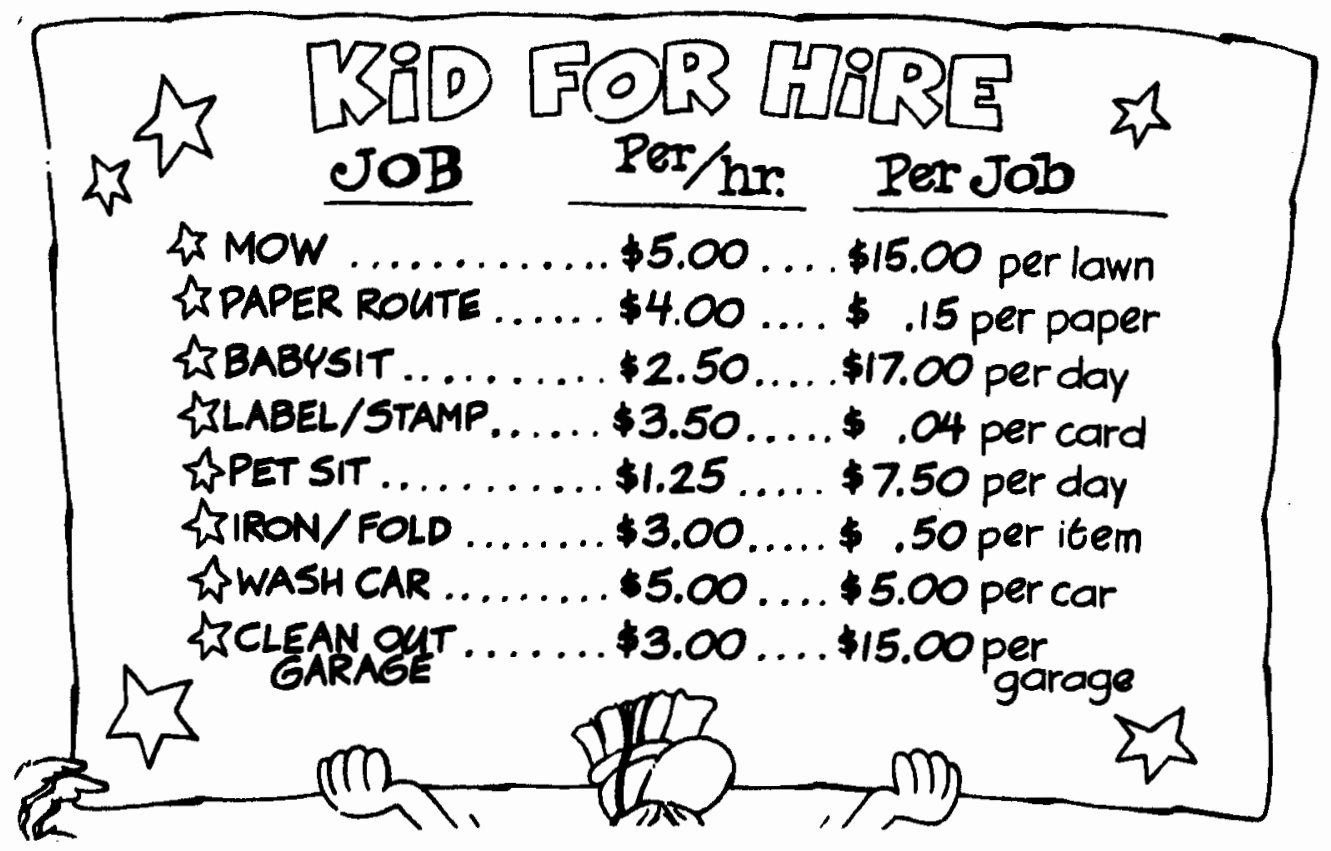

You spent 2 hours a day for a week pet-sitting the McCauley's dog. When they returned from vacation, Mr. McCauley gave you $\$ 21.00$. How much per hour did he pay you? Did he pay you more or less then the per hour rate on the chart? 
Session 2

Name

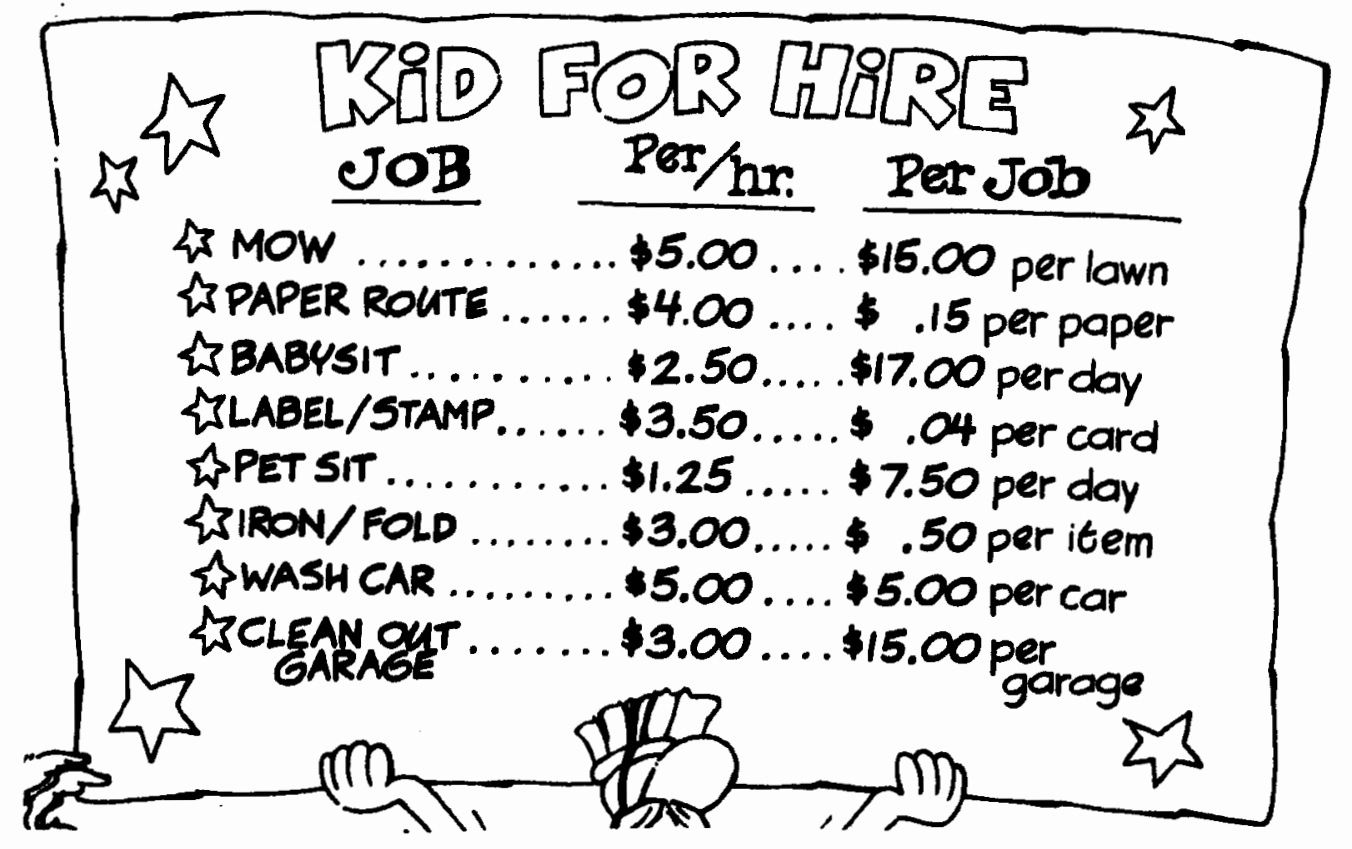

You babysat for the Rollman children all day yesterday. You were there 8 hours. Would you rather be paid per hour or per job? Why? 
Name

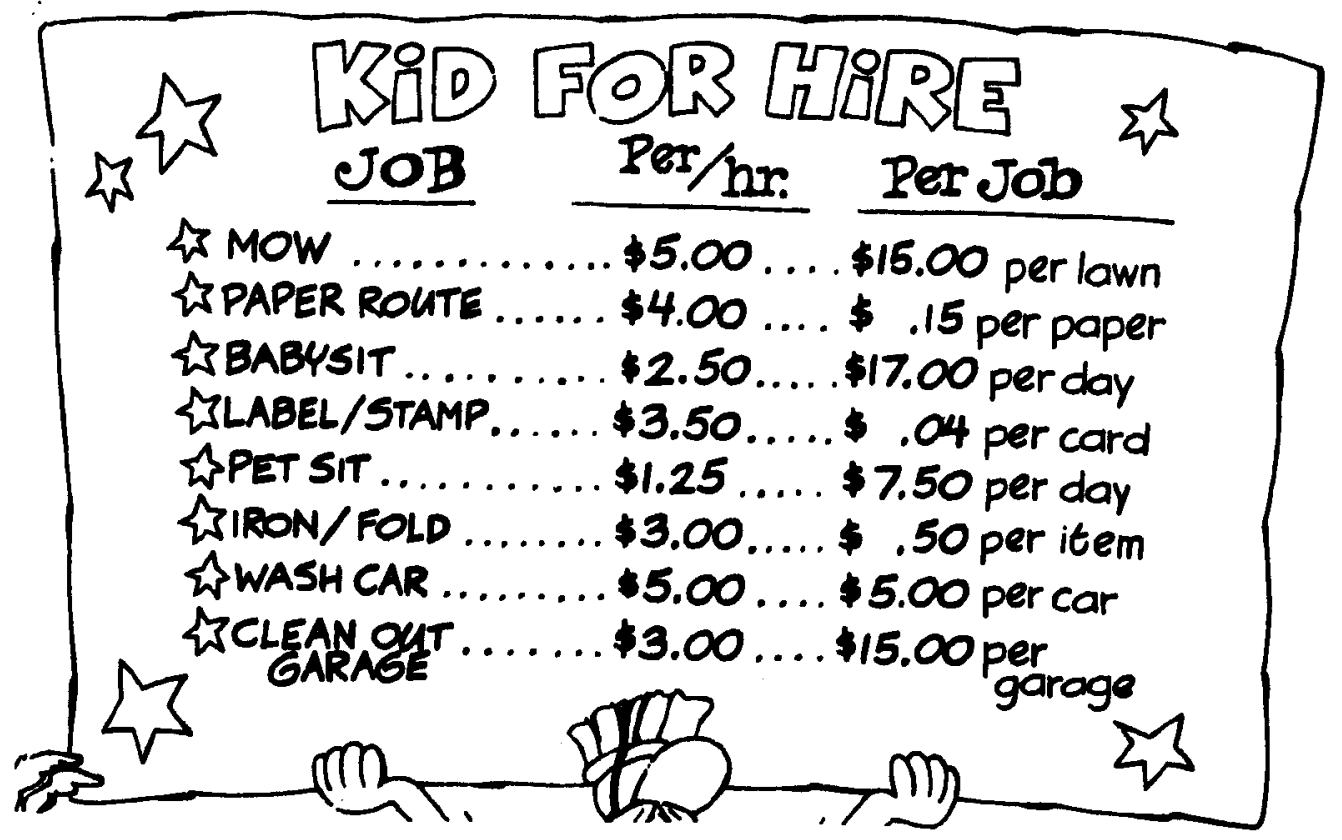

You delivered 43 papers in 2 hours. Will you make more money if you charged per hour or per job? How much more? 
Name

In a football game last year the Rams outscored the Huskies 29 to 19. Use the following information to explain how the teams could have obtained those scores.

Touchdown $=6$ points Safety $=2$ points
Point After = 1 point Field Goal $=3$ points 
Name

Charlie and his friends went to the county fair. They spent 1 hour twenty minutes riding the rides. They played games at the booths for 45 minutes, visited the exhibits for half an hour then went to the Fun House for fifteen minutes before going home. How long did Charlie and his friends stay at the fair? 
Name

Helene cleaned Mrs. McCauley's jeep. She worked from 3:30 p.m. - 8:00 p.m. She charged $\$ 5.00$ per hour. How much did Helene make? 
Name

\section{BETTY'S BAGELS}

INDIVIDUAL (1-5)

$\$ .59$

INDIVIDUAL (7+)

$\$ .50$

HALF DOZEN (6)

$\$ 2.99$

\section{BETTY'S DOZEN (13) \\ $\$ 4.99$}

Your soccer team is having a special team breakfast and you need to take 18 bagels. You can buy the bagels using any combination of the choices listed above. Which combination will you buy?

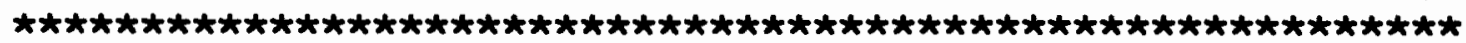

What questions do you have about the problem? Do you have an idea about how to solve the problem? 
Session 8

Name

Use the chart to come up with a combination of three jobs you could do to earn $\$ 50.00$. Which three jobs will you do? How many hours will you do each job?

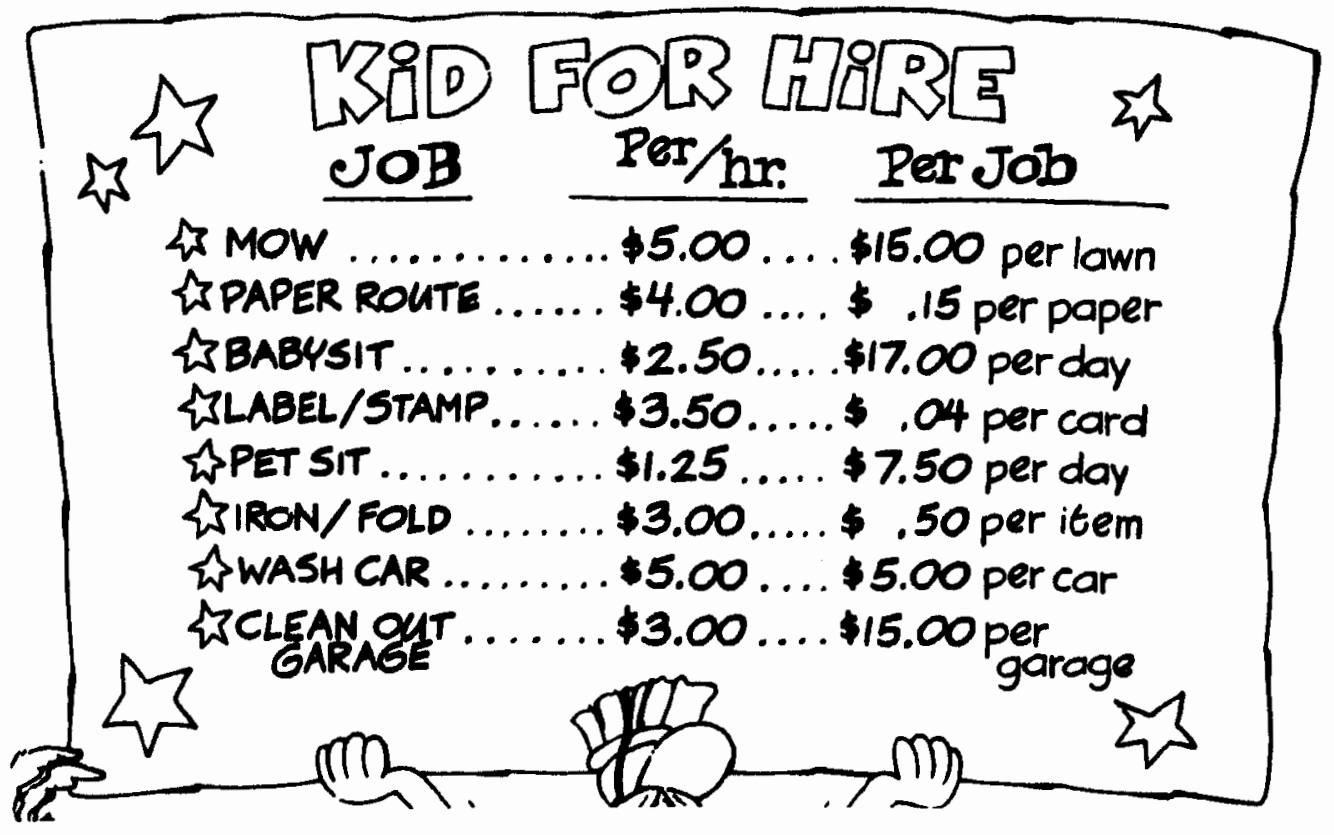


Name

\section{Tennis Ball Bounce}

Mason dropped a tennis ball from a balcony 16 feet above the sidewalk. Each time the ball bounced, it traveled half as high as the previous bounce. Mason's sister caught the ball when it bounced one foot from the sidewalk. How many times did the ball bounce?

How do you think the problem should be solved? 


\section{Putt-Putt Problems}

A putt-putt course owner has decided to replace the green turf on two of the putt-putt holes. Look at the shapes of the putt-putt holes below. Think about how you can calculate the area of the green turf because the greens are irregular shapes. Calculate the area of each putt-putt hole by developing a strategy for estimating the area of the green turf.

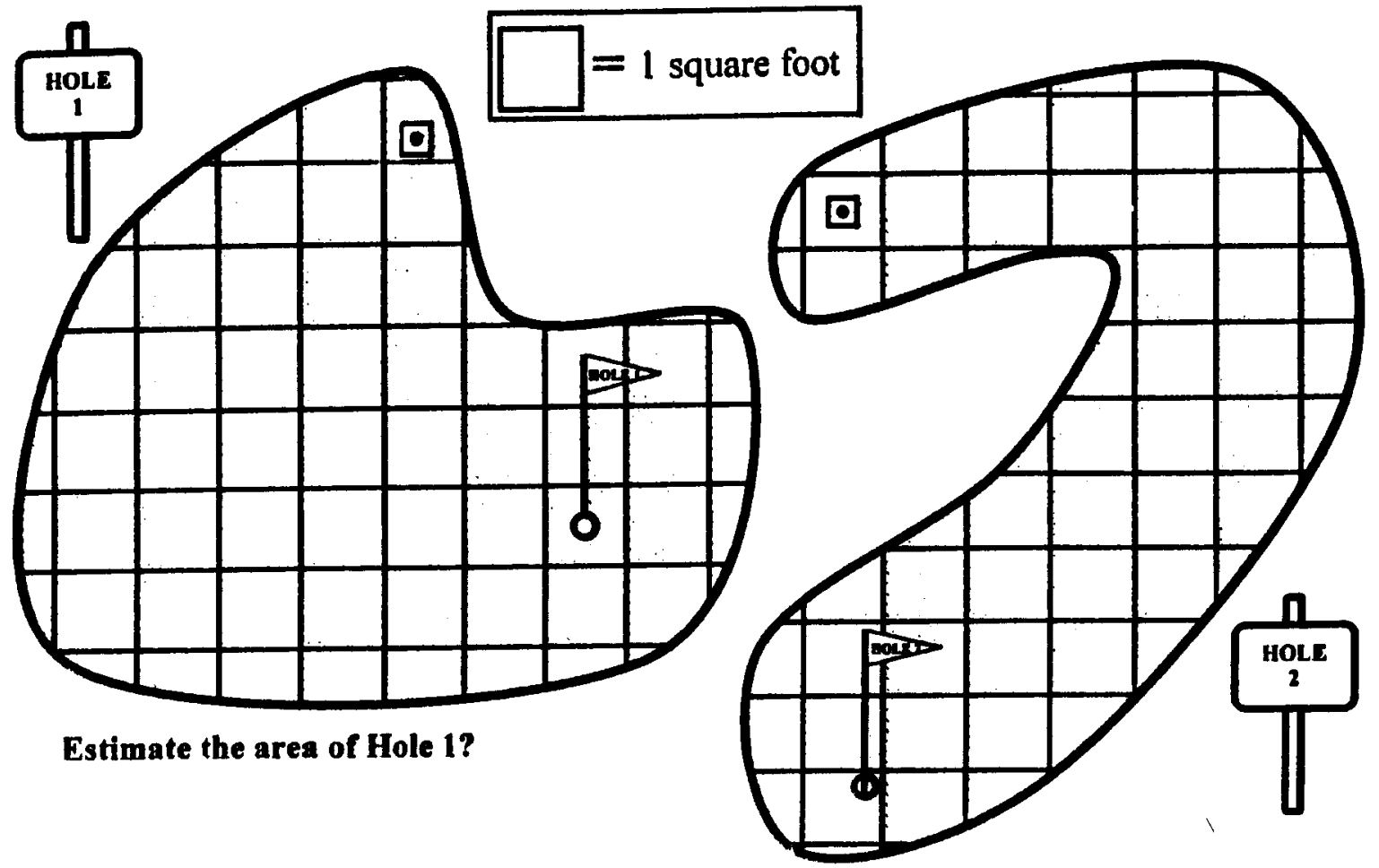

Estimate the area of Hole 2?

Describe the strategy you will use to estimate the area of the green turf in each puttputt hole. 
Exchange papers with your partner.

Partner's Name

Is your partner planning to use the same strategy as you? Will the strategy described work? Why or why not? 
Session 11

\section{Use the Distributive Property}

Putt-Putt Problems

Extension Activity 1

Examine the two putt-putt holes below. Use what you know about the area of rectangles to choose the hole you think is larger. Circle the hole you think has a larger turf area or put an "=" sign between them if you think they have the same area.
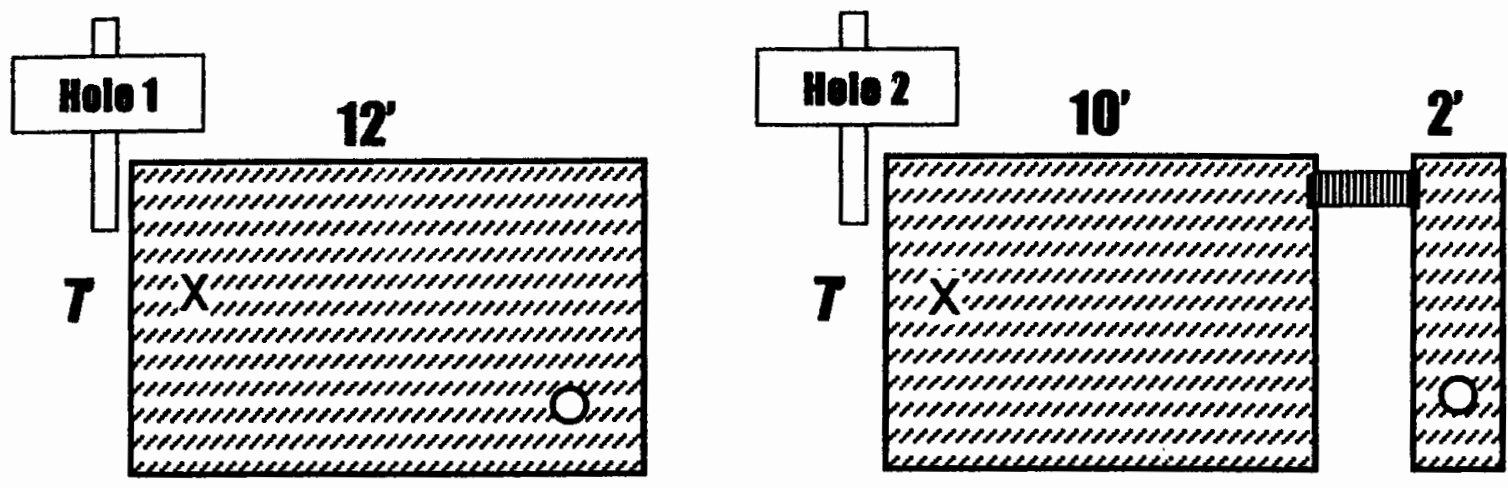

Use the space below to explain your prediction.

Calculate the area of each hole. To determine the total area of Hole 2, first multiply the length and width of each rectangle, and then add the products.

Area of Hole 1

Area of Hole 2

Describe what you discovered about the areas of the two holes. Did your calculations prove or disprove your prediction?

Use $<,>$, or $=$ to complete each equation. Solve each equation to prove your response.
1. $7 \times 8 \bigcirc(7 \times 5)+(7 \times 2)$
2. $15 \times 9 \bigcirc(10 \times 9)+(5 \times 9)$

3. $18 \times 6 \bigcirc(10 \times 6)+(10 \times 6) \quad 4.32 \times 4 \bigcirc(20 \times 4)+(10 \times 4)+(2 \times 4)$ 
Name

You have hired a company to build a fence. The workers inform you that it costs $\$ 200.00$ for each 10 feet of fence. You have them build a fence that is 35 feet. The company sends a bill for $\$ 800.00$. Should you pay the bill? Why or why not?

\section{Partner's Name}

Read the explanation written above. Do you agree with what is written? Write to your partner and tell them what you think about their explanation. 


\section{Check It Out}

You are helping the school librarian count the books in the library. Use the Total Owned and the Total Counted columns of the chart to fill in the Number Missing column. Then, use the chart to answer the questions at the bottom of the page.

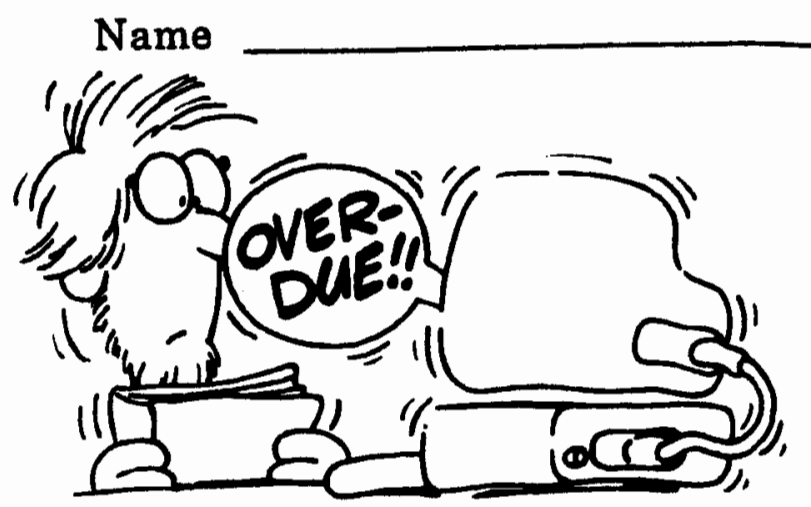

\begin{tabular}{|c|c|c|c|c|}
\hline Book Title & Total Owned & $\begin{array}{c}\text { Total on } \\
\text { Hand }\end{array}$ & $\begin{array}{c}\text { Number } \\
\text { Missing }\end{array}$ & $\begin{array}{c}\text { Cost to } \\
\text { Replace One } \\
\text { Copy }\end{array}$ \\
\hline Funny Bones & 3 & 3 & & $\$ 2.95$ \\
\hline In the Window & 2 & 1 & & $\$ 6.95$ \\
\hline Fishing Fred & 1 & 1 & & $\$ 1.95$ \\
\hline Hand Puppets & 2 & 0 & & $\$ 7.99$ \\
\hline My Pesky Pet & 4 & 0 & & $\$ 3.95$ \\
\hline Happy Daze & 3 & 2 & & $\$ 2.95$ \\
\hline
\end{tabular}

Describe how you will figure out the number of books missing from the library. 
Exchange papers with your partner. Partner's Name

Read the strategy your partner is going to use to figure out how many books are missing from the library. Do you think their strategy will work? Why or why not? 


\section{4-Nothing More!}

Suppose you need to cut a piece of fabric exactly 34 inches long off a bolt of cloth. You have four pieces

of string that measure 1 inch, 3 inches, 9 inches, and 27 inches.

How can you measure the 34-inch length using each piece of string just once? 


\section{A Frealthful Treat}

Kelsey and her friend pooled their money to buy a granola bar. Here's how they cut the bar to share it.

If the whole bar cost $\mathbf{\$ 1 . 5 0 ,}$ what is the cost of Kelsey's share?

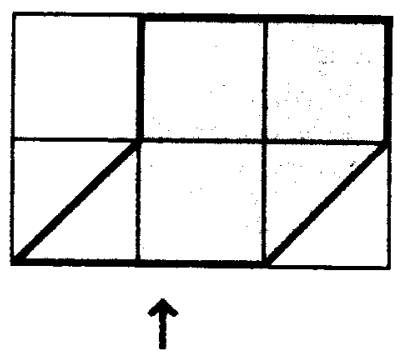

Kelsey's Share 
Name

You just received this letter.

May 24, 2004

Dear Student,

I am interested in buying new carpet for my living room.

Please let me know how much carpet I will need to purchase.

Sincerely,

Write back to Ms. DeWitt and let her know what information you need and how you will calculate the area of her living room. 


\section{A Weighty Problem}

The sphere $\bigcirc$ weighs 4 pounds.
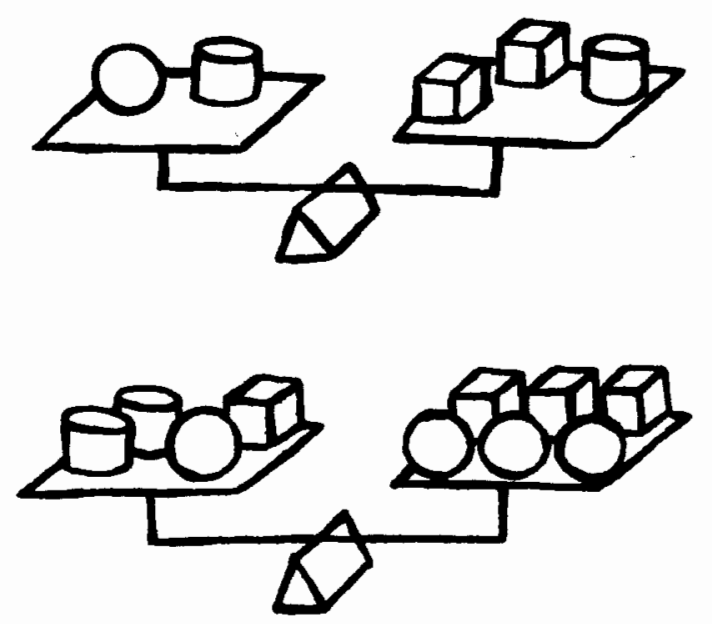

What is the weight of the cylinder $\square$ ?

What is the weight of the cube $\square$ ? 
Appendix E

Pre-Brief Constructed Response Items 
Name

Daily Challenge

Draw a figure that shows $3 / 8$.

Use what you know about fractions to explain why your drawing is correct. 
Name

Daily Challenge

You are given a bag of M\&M's with 3 red, 6 brown, 4 green, 3 yellow, and 2 orange candies. What is the probability that you will choose a brown candy? Write your answer as a fraction.

Using what you know about probability, justify your answer. 
Pre BCR \#3

Name

Daily Challenge

Write two equivalent fractions for $\frac{1}{2}$.

Using what you know about fractions, explain how you solved the problem. Be sure to use math words in your explanation 
Name

Ms. DeWitt wants to buy a card for each of the 16 fourth grade students. Each pack of cards has five cards. How many packs will she need to purchase?

Explain how you know your answer is correct. You can use words, numbers and /or representations in your explanation. 
Pre BCR \#5

Cecilia is drawing rectangles on a grid. One of her rectangles looks like this:

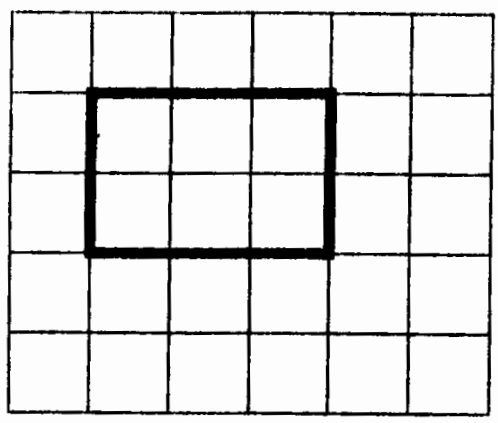

Draw a rectangle with an area of 12 square units.

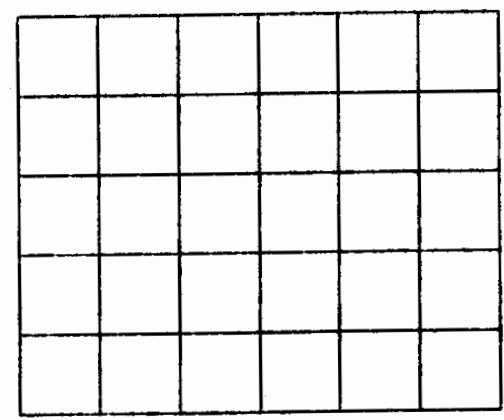

Use what you know about area to explain why your drawing is correct. Use words, numbers, and/or pictures in your explanation. 
Genevive needs to continue this pattern:
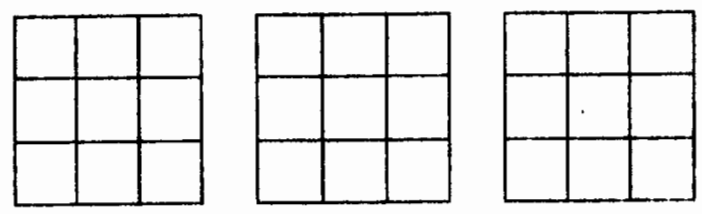

Draw the next shape in the pattern.

Use what you know about patterns to explain why your answer is correct. 
Mark is collecting information about the kinds of pets that third-graders have. He found out the following information:

10 students have birds. 20 students have fish.
30 students have dogs.

50 students have cats.

In the space below, create a pictograph that shows the information that Mark collected. Let each of your pictures stand for 10 students. Remember to include a title and a key for your pictograph.

Use what you know about pictographs to explain why your drawing is correct. Use words and/or numbers in your explanation. 
Appendix F

Post Brief Constructed Response Items 
Post BCR \#1

Name

Daily Challenge

Scott had earned $\$ 3.00$. He has decided to spend it all on soda ad bubble gum at Gibson's Store. Sod cost's $\$ .75$ a can. Bubble gum is on sale today. It usually costs $\$ .20$ for one piece. But today Scott can buy two pieces for $\$ .25$. If Scott buys one can of soda and spends the rest of his money on bubble gum, how many pieces of gum can he buy?

Answer:

Explain how you solved the problem. 
Name

Your friend asks you to help him with his homework. His teacher gave the following problem.

\section{Spring Festival}

The Spring Festival at River View Elementary was last week. Tickets were sold 5 for $\$ 1.00$. How many tickets would you get for $\$ 10.00$ ?

Write to your friend and tell them how you think they should solve the problem. Do not tell them the answer. 
Fuil House

How many people live in eaca kid's house?

Use the ches to find out.

Write each kid's name below the graph.

- In Kristen's house, there are 3 times as mory people-as-pets.

- There is an odd number of people and an odd number of pets in Ben's house.

- There is a total of 9 people and pets in Lisa's house. with more pets than people.

- In Mike's house, there are 3 fewer pets than people.

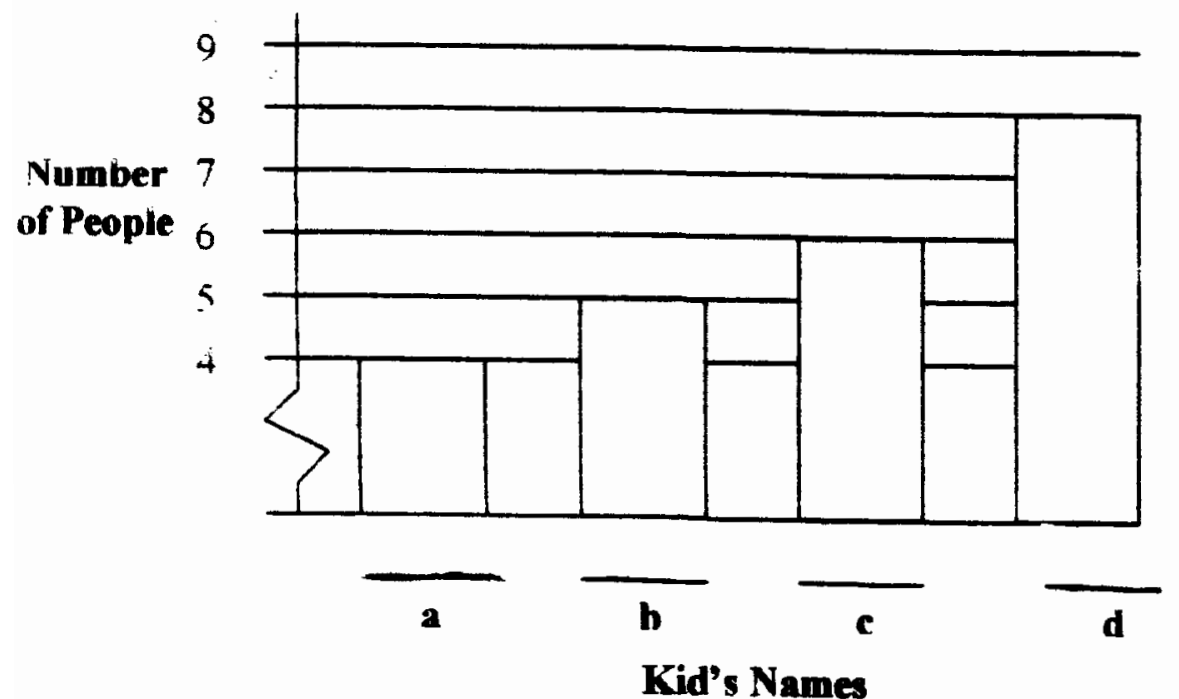

in the area to the right, convince your parther that your answer is correct. Although you may wish to show your work as support for your argument, your argument should tell why you know you're right! 
Name

Daily Challenge

Joey and Eric asked their classmates this question: What is your favorite kind of fruit? Here is a list they made from the answers.

\begin{tabular}{|c|c|}
\hline Student & Favorite Fruit \\
\hline Joey & orange \\
\hline Eric & peach \\
\hline Beth & banana \\
\hline Donna & apple \\
\hline Steve & apple \\
\hline Ali & banana \\
\hline Tim & orange \\
\hline Jeff & apple \\
\hline Craig & orange \\
\hline Tyler & apple \\
\hline David & banana \\
\hline Carol & banana \\
\hline Jenny & peach \\
\hline
\end{tabular}

Create a bar graph to display the data in the list. Se sure you label all parts of the graph. 
Post BCR \#5

Name

Daily Challenge

Your Mom sends you to the store to purchase three boxes of ice cream sandwiches. Which of the two brands is the better buy? Show how you calculated which brand is the better buy, circle your choice.

Brand A

\begin{tabular}{|c|}
\hline Ice Cream \\
Sandwiches \\
3 boxes for $\$ 8.79$ \\
\hline
\end{tabular}

Brand B

Ice Cream

Sandwiches

$\$ 2.95$ per box

Write what you would say to your Mom to convince her you made the best choice. 